\title{
Evaluation of a Patient-Specific, Low-Cost, 3-Dimensional-Printed Transesophageal Echocardiography Human Heart Phantom
}

\author{
Dissertation \\ zur \\ Erlangung des akademischen Grades \\ Doctor medicinae (Dr. med.) \\ an der Medizinischen Fakultät \\ der Universität Leipzig
}

Eingereicht von: Massimiliano Meineri,

Geboren am 1. März 1974 in Pinerolo, Italien

Angefertigt an:

der Abteilung für Anästhesiologie und Intensivmedizin, Herzzentrum Leipzig,

Betreuer:

Prof. Dr. med. habil. Joerg Ender

Beschluss über die Verleihung des Doktorgrades vom: 19.10.2021 
Table of Content

1. Bibliographic Description 3

2. Introduction 4

2.1. Perioperative transesophageal echocardiography 4

2.2. Transesophageal echocardiography training 5

2.3. Transesophageal echocardiography simulation 6

2.4. 3D Heart Printing 13

$\begin{array}{ll}\text { 2.5. 3D Segmentation } & 16\end{array}$

$\begin{array}{ll}\text { 2.6. Development of the study phantom } & 17\end{array}$

2.7. Study Rationale $\quad 18$

3. Publication 22

$\begin{array}{ll}\text { 4. Summary } & 30\end{array}$

5. References 33

$\begin{array}{ll}\text { 6. Appendices } & 37\end{array}$

6.1. Darstellung des eigenes Beitrags $\quad 38$

6.2. Erklärung über die eigenständige Abfassung der Arbeit 39

$\begin{array}{ll}\text { 6.3. Lebenslauf } & 40\end{array}$

6.4. Publikationen und Vorträge 44

$\begin{array}{lc}\text { 6.5. Danksagung } & 61\end{array}$ 


\title{
1. Bibliographic Description
}

\section{Massimiliano Meineri}

\section{Evaluation of a Patient-Specific, Low-Cost, 3-Dimensional-Printed Transesophageal Echocardiography Human Heart Phantom}

\author{
Dissertation, University of Leipzig
}

\section{Pages 61, References 34, Figures 9, Appendices 5}

\section{Presentation}

Currently available 3D modelling and printing techniques allow for creation of patientspecific models based on 3D medical imaging data. We hypothesized that a low-cost, patientspecific, cardiac CT-based phantom, created using desktop 3D printing and casting had comparable image quality, accuracy and usability as an existing commercially available echocardiographic phantom.

We conducted a blinded comparative study in the simulation laboratory at a single academic institution. We recruited ten voluntary cardiac anesthesiologists. Stage one of the study consisted of an on-line questionnaire where a set of basic TEE views obtained from the 3D printed phantom and commercial phantom were presented to participants who had to identify the views and evaluate their fidelity to clinical images on a 1-5 Likert scale. In stage two, participants performed an unblinded basic TEE examination on both phantoms.

The time needed to acquire each basic view was recorded. Overall usability of the phantoms was assessed through a questionnaire. The participants could recognize most of the views. Fidelity ratings for both phantoms were generally similar. The time required to obtain the views was shorter for the $3 \mathrm{D}$ printed phantom for which the overall user experience was also better.

The study suggests that a $3 \mathrm{D}$ printed TEE phantom is comparable to the commercially available one with good usability. 


\section{Introduction}

\subsection{Perioperative transesophageal echocardiography}

Transesophageal echocardiography (TEE) has become standard in the intraoperative care of cardiac surgical patients. For the past three decades cardiac anesthesiologists have been trained to perform comprehensive intraoperative TEE examinations and developed certification pathways through the National Board of Echocardiography in the USA ${ }^{1}$ and the European Association of Cardiothoracic Anesthesiologists in Europe ${ }^{2}$. Training in Comprehensive TEE is typically achieved through a fellowship in cardiothoracic anesthesiology and the development of an exam portfolio during supervised hands-on practice $^{3}$. The increased availability of TEE equipment and trained anesthesiologists has spread its use outside of the cardiac operating room on critically ill, unstable and high-risk patients to rule out major cardiac pathologies and optimize hemodynamics. TEE allows assessment of cardiac and valvular function, pericardial and pleural effusions with images that are significantly higher in quality and reproducibility compared to transthoracic echocardiography (TTE) and without interfering with most surgical procedures or cardiopulmonary resuscitation. A comprehensive TEE examination includes 28 Standard views and multiple measurements to quantify valves and ventricular function. A simplified eleven views (basic) TEE examination ${ }^{4}$ (Fig. 1) has been developed to be used outside the cardiac operating room to answer dichotomous questions. It includes eleven standard views and minimal set of measurements. The expanded use of TEE has increased the need for training especially in basic TEE since its endorsement by the Society of Cardiovascular Anesthesiologists ${ }^{4}$. A further simplification of the TEE exam to 5 views has been proposed for the use during resuscitation in the emergency medicine setting ${ }^{5}$. The introduction of pointof-care ultrasound in the perioperative scenario as well as the use of ultrasound for blocks and line insertion has increased the number of available ultrasound machines which now commonly support the use of TEE probes. 
These factors contribute to the growing demand for TEE training.

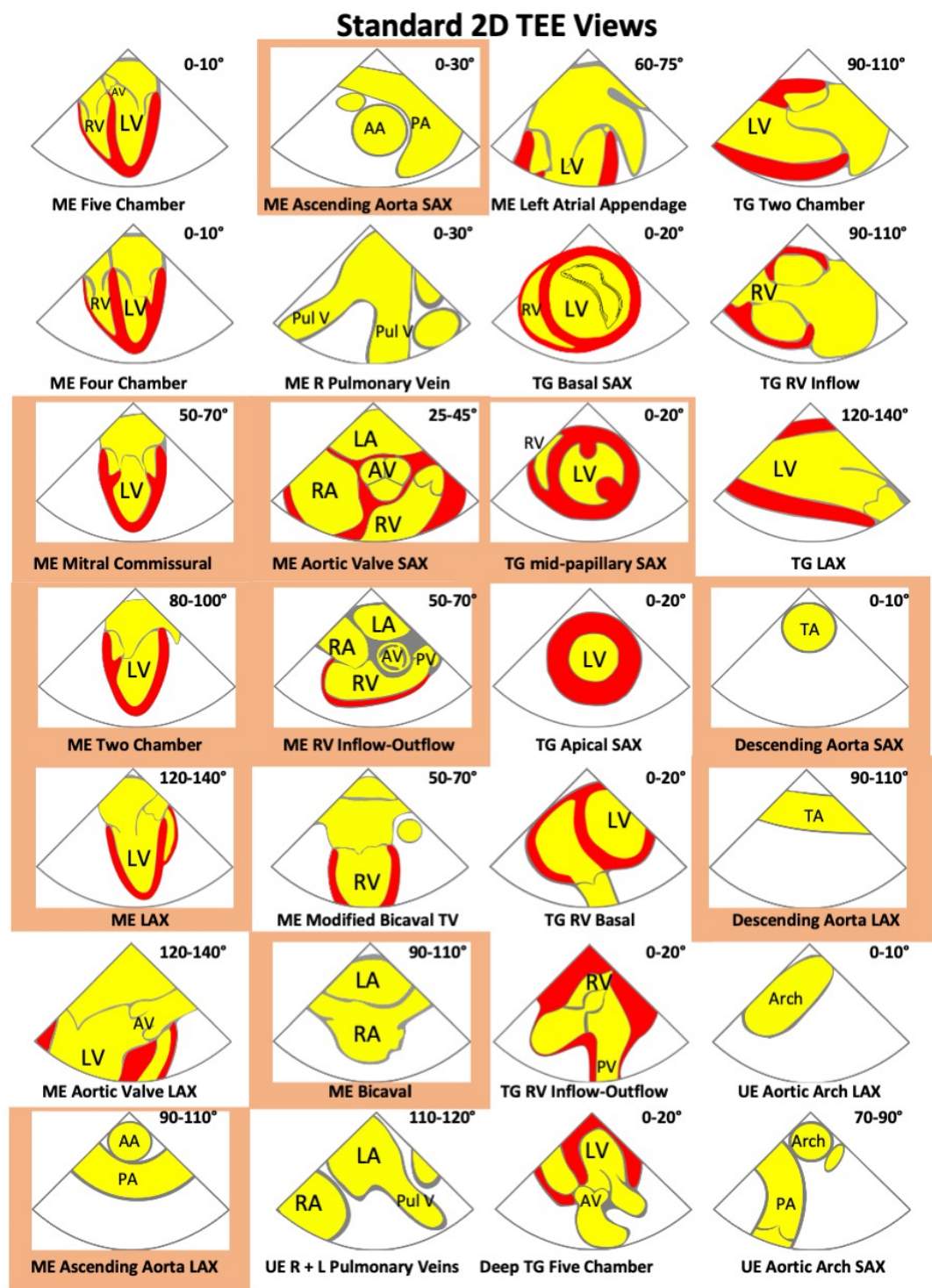

Figure 1: Standard 28 TEE and highlighted the 11 basic views. ME: mid-esophageal, TG: T'trans-gastric, UE: upper-esophageal, SAX: short axis, LAX: long axis, LV: left ventricle, RV: right ventricle, LA: left Atrium, RA: right atrium, AV: aortic valve, PV: pulmonic valve, Pul V: pulmonary vein, AA: ascending aorta, PA: Pulmonary artery, Arch: Aortic Arch.

\subsection{Transesophageal echocardiography training}

The I-AIM framework defined the four pillars of the practice of clinical ultrasound ${ }^{6}$ :

- Indication

- Image Acquisition 
- Image Interpretation

- Medical decision making.

Among all these four essential elements, image acquisition skills remains the stumbling block in learning clinical ultrasound. It requires some theoretical elements such as: understanding of three-dimensional cardiac anatomy, ultrasound physics, principles of image generation, machine settings and image optimization. At the same time, it comprises manual skills such as: probe handling and hand-eye coordination.

Historically, image acquisition has been learnt through hands-on practice on patients. This rises however, several safety concerns regarding the invasiveness of TEE and possible complications. In awake patients, TEE exam is quite uncomfortable, and its duration should be limited but also in anesthetized patients TEE probe manipulation is not hazard-free. In the hand of experts, intraoperative TEE carries a $0.2 \%$ overall incidence of complications which include major bleeding and esophageal perforation which may result in significant morbidity and mortality ${ }^{7}$. Furthermore, during cardiac surgical procedures, the time to perform a comprehensive TEE is often limited by the time from skin incision and the initiation of cardiopulmonary bypass. This leaves often little spare time for trainees to practice basic views acquisition without interfering with standard patients' care.

\subsection{Transesophageal echocardiography simulation}

TEE training has greatly benefitted from the use of simulation.

Simulation comprises several different modalities:

- On-line simulators

- High fidelity simulators

- Augmented reality

- Phantoms

On-line simulators include modules with progressive degrees of complexity and interactivity, from interactive 3D Anatomy modules to full functioning simulators. 
They have been developed to address the learning needs related to image acquisition and anatomical correlation that consist of 3D representation of cardiac anatomy on a set of twodimensional images and spatial probe manipulation.

Interactive 3D Sono-anatomy modules have helped the users to understand the correlation between TEE standard views and three-dimensional cardiac anatomy. They consist of realistic, high fidelity three-dimensional models of the heart that can be "grabbed" and freely rotated in virtual space (Fig. 2). The Ultrasound plane that generates the corresponding TEE standard view is displayed in its position and can be seen on the surface of the heart. The 3D heart model has been developed based on a real cardiac CT scan and can be sliced along the US plane of cut to reveal the details of the internal anatomy and match it with the corresponding view.

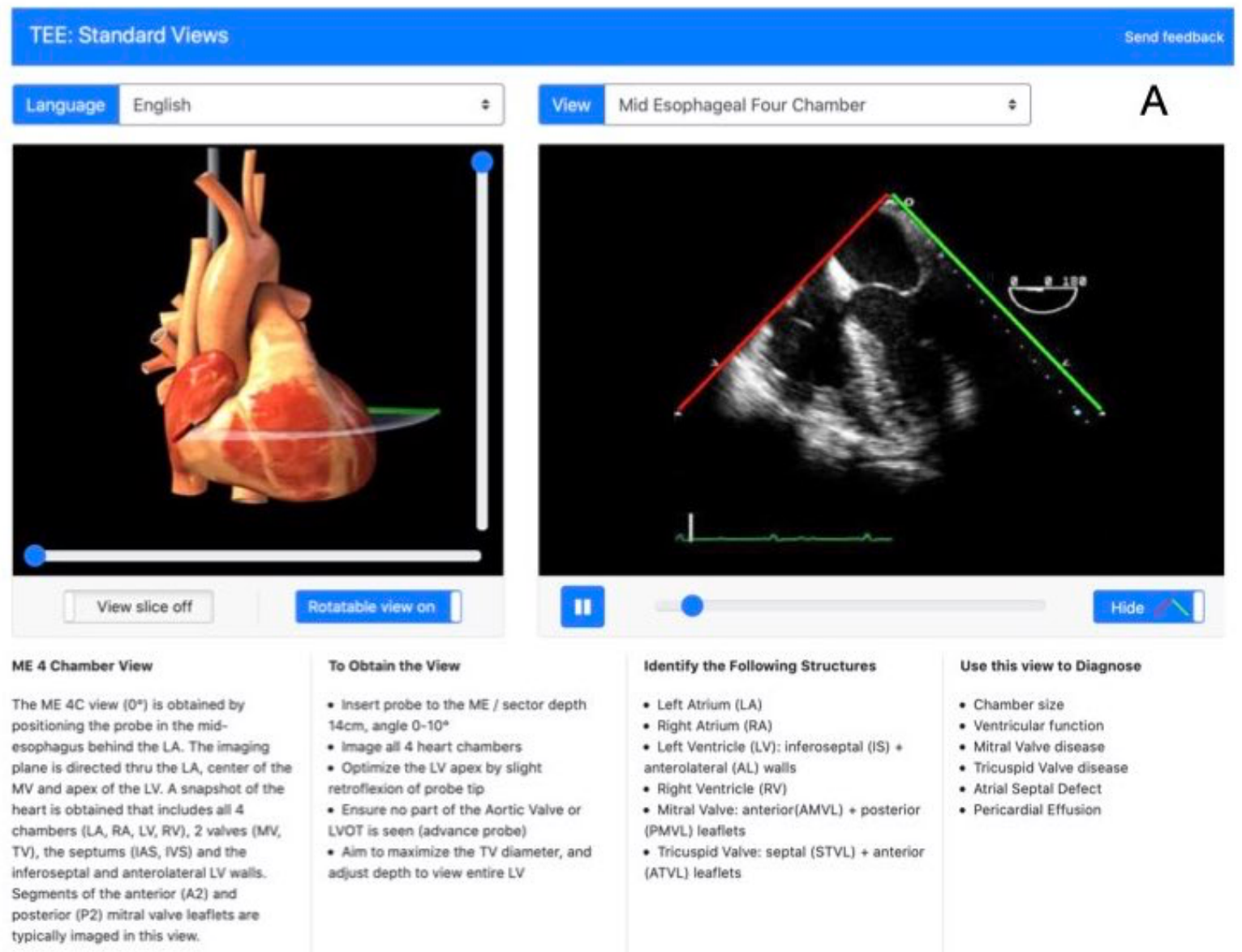




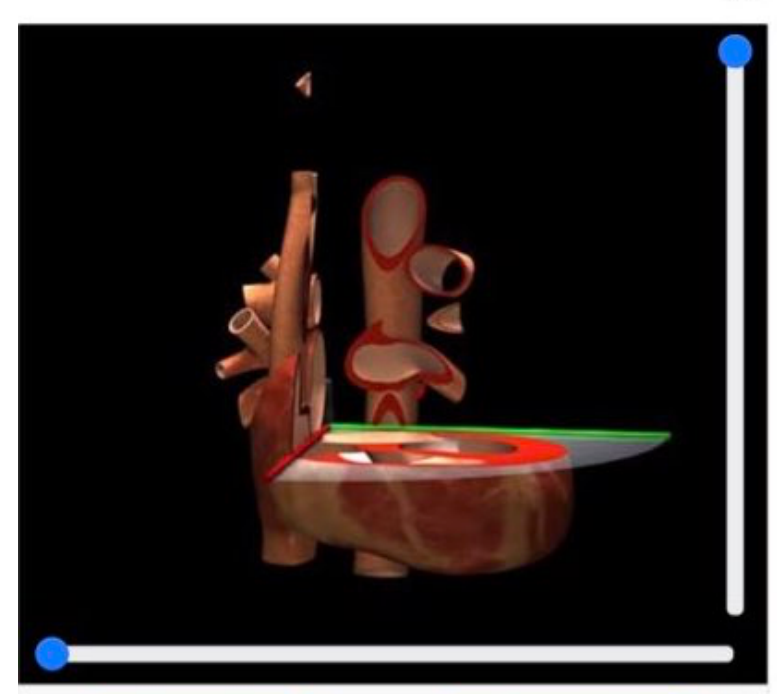

View slice on

Rotatable view on

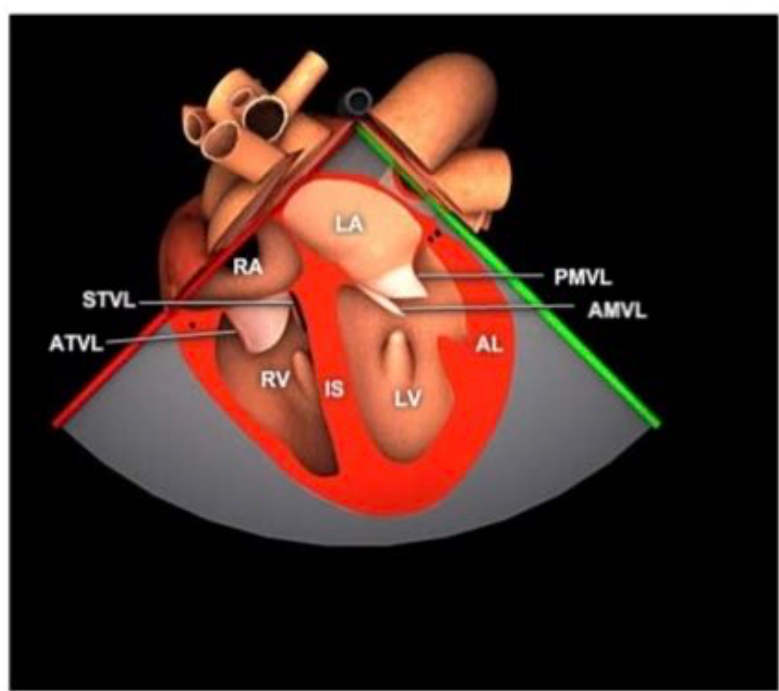

Labels on

Rotatable view off

Figure 2: Interactive on-line free 3D Sono-anatomy module. A: Staring page where the user can choose from 20 standard TEE views. The standard 2D image is played on the right and the $3 \mathrm{D}$ heart model with the TEE probe and Scanning plan corresponding to the view on the left; B: the 3D heart model can be cut along the TEE scanning plane; $\mathrm{C}$ : The cut $3 \mathrm{D}$ model can be oriented to match the real $2 \mathrm{D}$ image and labels can be activated.

From: www.pie.med.utoronto.ca

The use of these modules for independent unsupervised learning demonstrated to improve knowledge of TEE views and cardiac anatomy in novices ${ }^{8}$ and to be an effective adjuvant to simulator raining. ${ }^{9}$ On-line simulators simulate a TEE exam and the transition between views. In the model proposed by the Toronto General Hospital Anesthesia group (Fig. 3) navigation through 20 standard TEE views has been simplified to 5 basic probe movements: advance, withdraw, rotate right, rotate left and anteflex. In a map-like chart all views can be then connected by a different colored arrow which indicates one of the basic 5 above mentioned movements. The correct scanning angle is also indicated for each view. This chart is the roadmap for a $3 \mathrm{D}$ animation of the probe and scanning plane movement between twenty standard TEE views therefore simulating a complete TEE exam. The user can select a specific view and the simulator would show the movement of the probe from the current to the 
selected position. The interaction with the simulator does not albeit allow direct probe manipulation and change in scanning angle.
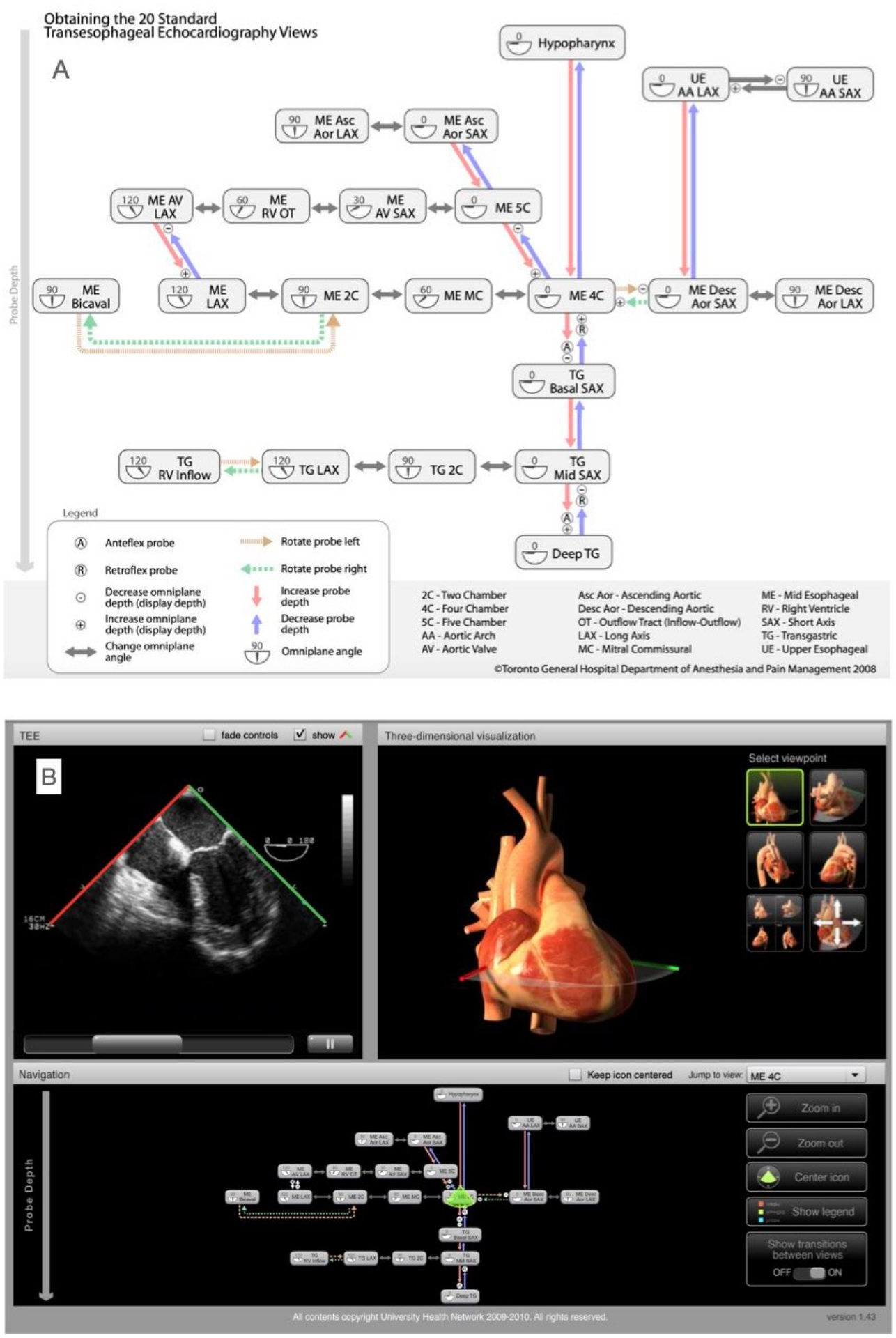

Figure 3: On line simulator. A: road map to navigate the 20 standard views. The probe movements to move between views are simplified to four and change in scanning angle. Each movement corresponds to a colored arrow. B: Start page for the TEE simulator. The roadmap is used to move between views. The probe movement 
is displayed in the 3D Heart model and the corresponding transition image on the top left panel. Once a view is reached the $3 \mathrm{D}$ model can be further manipulated to display the inside along the TEE scanning plane.

From: www.pie.med.utoronto.ca

The simulator demonstrated excellent usability and an hour of unsupervised simulator use resulted in a significant impact on novices theoretical knowledge of probe manipulation and image acquisition. ${ }^{10}$

On-line simulators provide the opportunity for any realistic probe movement and change in scanning angle and display a computer-generated representation of the resulting TEE view. There are two free on-line simulators (Perioperative Interactive Education and Advanced Perioperative Imaging Lab) (Fig 4), both developed by the Toronto General Hospital Anesthesia group. They rely on the videogaming engine "Unity" (Unity Technology, San Francisco CA, USA) because it allows "rendering on the fly". The 3D images are not preloaded but are generated "on demand" as the user moves the probe, which allows to spare significant amount of computer memory and time to load the $3 \mathrm{D}$ datasets to make them visible.

By clicking different buttons, the user has infinite degrees of movement of the probe handle and tip as well as the scanning angle. The Scanning plane can be seen on a realistic and accurate Ct-based 3D reconstruction of the heart side-by-side with a beating ultrasound image. The one form the Advanced perioperative Imaging lab allows to load different heart models with pathology and could be potentially used for patient-specific simulation. It uses the latest version of Unity software that allows for display in Virtual reality environment. To date no studies have been conducted to test the usability and educational impact of these simulators. 

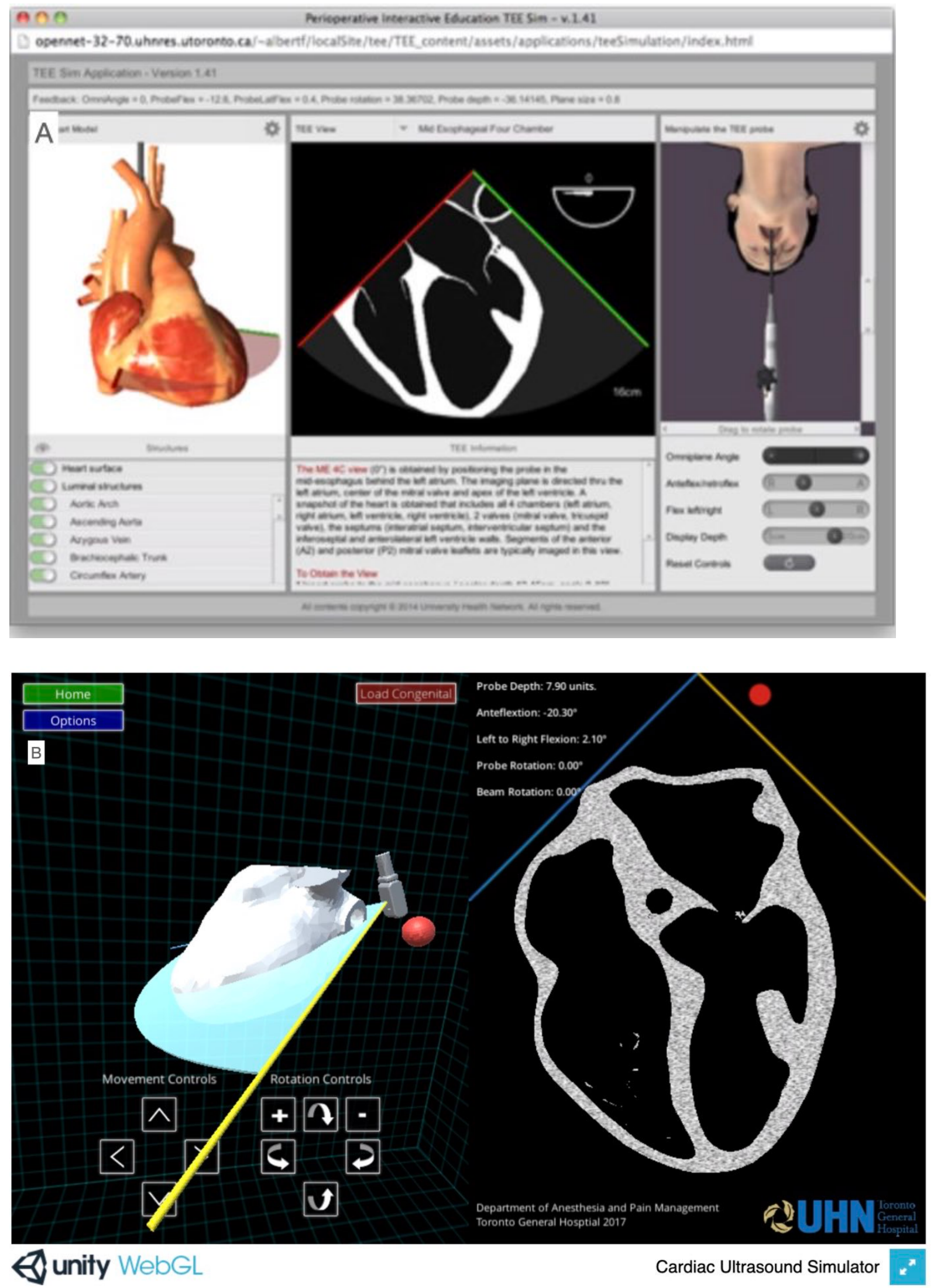

Figure 4: On line Simulators. A: from: www.pie.med .utoronto.ca; B: from: www.apil.ca 
Full-scale high fidelity echocardiography simulators have been introduced into the market in the late 2000'sand have become a standard of training specially for TEE. They consist of a mannequin representing the patient torso and head with an opening at the mouth where the TEE probe can be introduced. The probe is modelled on a real TEE probe and contains the same controls: a knob for ante-retro, right-left flexion and two buttons to increase and decrease the scanning angle. The Mannequin contains an electromagnetic tracking system that detects the probe position and movements in respect to the heart. The probe and the mannequin are connected to a computer that merges all this information and generates a realistic TEE image together with a beating, real-time, three-dimensional representation of the heart, the probe and the scanning plane. The details of heart anatomy along the scanning plane are displayed in the same orientation of the TEE image to allow direct anatomical correlations. The three-dimensional rendering of the heart serves as an augmented reality tool that can be further manipulated to display labels for anatomical details or to perform a virtual dissection. The use of TEE simulators has a significant impact on the learning curve to acquire standard TEE views ${ }^{11}$. As a sole mean of training, they demonstrated to be effective in teaching Focused TEE views with excellent knowledge retention ${ }^{12}$. Given their ability to track the probe movement in three-dimensional space and their ability to display realistic cardiac pathology they can also be used as a testing tool to assess skills. 

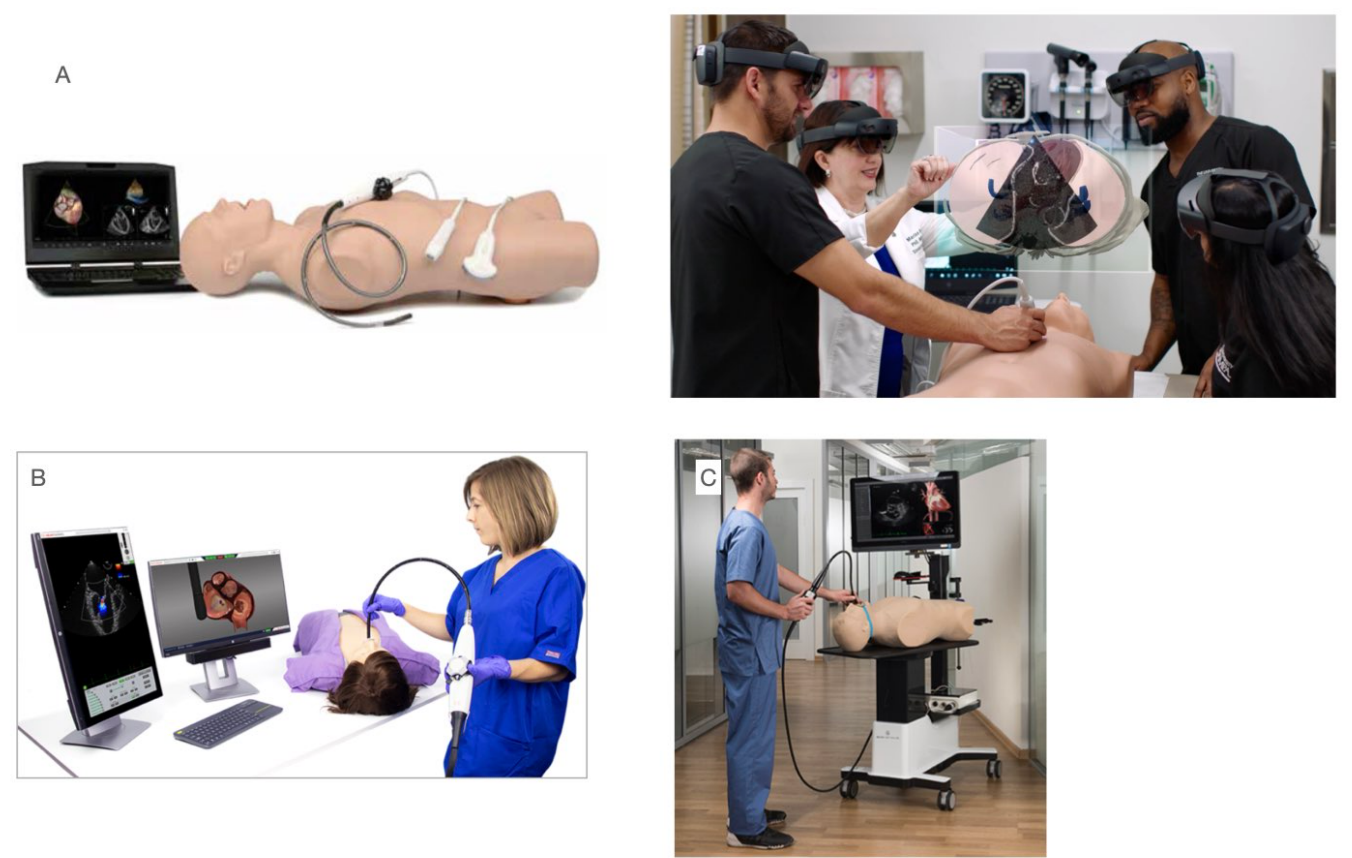

Figure 5: Full-scale commercially available high-fidelity simulators. A: Vimedix ${ }^{\mathrm{TM}}$ (CAE, Montreal, QC, Canada); B: Hearworks ${ }^{\mathrm{TM}}$ (Heartworks, London, UK); C: 3D Systems ${ }^{\mathrm{TM}}$ (3D Systems, Rock Hill, SC, USA)

To enhance the learning experience and expand the sensorial modalities some simulators allow integration of a virtual reality headset (Fig. $5 \mathrm{~A})^{13}$. The augmented reality displays a transparent three-dimensional model of the heart augmented reality as floating above the mannequin or makes the mannequin transparent allowing direct dissection along a plane in front of to the user's sight just by getting close to it.

The main limitations of high-fidelity simulators are their elevated cost, the degree of realistic representation of cardiac anatomy and simulated ultrasound images and the lack of a realistic user interface (they are all computer-based and do not simulate a specific echocardiographic machine).

Ultrasound phantoms are artefacts made from echogenic material that generate an ultrasound image using conventional Ultrasound systems. Any material that has the same ultrasound characteristic of soft tissue can be used to build a phantom. These include artificial materials such as gelatins, that can be perishable (edible gelatin, agar, or tofu $)^{14}$ or non-perishable 
(artificial gel) ${ }^{15}$. Biological material can also been used such as meat and gelatinous fruit and combined to simulate human tissue structure ${ }^{16}$ and whole animal organs such as pig hearts ${ }^{17}$. Ultrasound phantoms have been mostly used for measurements calibration ${ }^{18}$ and for task training ${ }^{14}$.

Ultrasound heart phantoms would be particularly useful in TEE training because they allow the user to perform an exam using a standard probe and ultrasound system therefore allowing real image optimization and machine interface training.

Developing an ultrasound heart phantom poses several challenges, due to the extreme complexity of its anatomy and the simulation of its physiological movement. Two types of TEE phantoms have been described so far: static and dynamic. A static heart phantom (Fig. 6) comprises a mannequin with a torso and a head where the probe is inserted into the mouth opening and advanced into the esophagus that lies in respect to the heart in a correct anatomical relationship. The heart lies on the chest and it is surrounded by ribs and air-filled lungs therefore allows for a realistic simulation of transthoracic echocardiography. Furthermore, the pericardium is connected to a set of external tubing that can be filled to simulate pericardial effusion and perform emergency needle pericardiocentesis. Some of the limitation of this phantom include its cost (more than 20,000 Euro) and the lack of specifications on how the 3D heart model was developed. The heart is realistic but was not modelled on a real scanned human heart. The inner part of the phantom is made with a proprietary Zerdyne gel. 

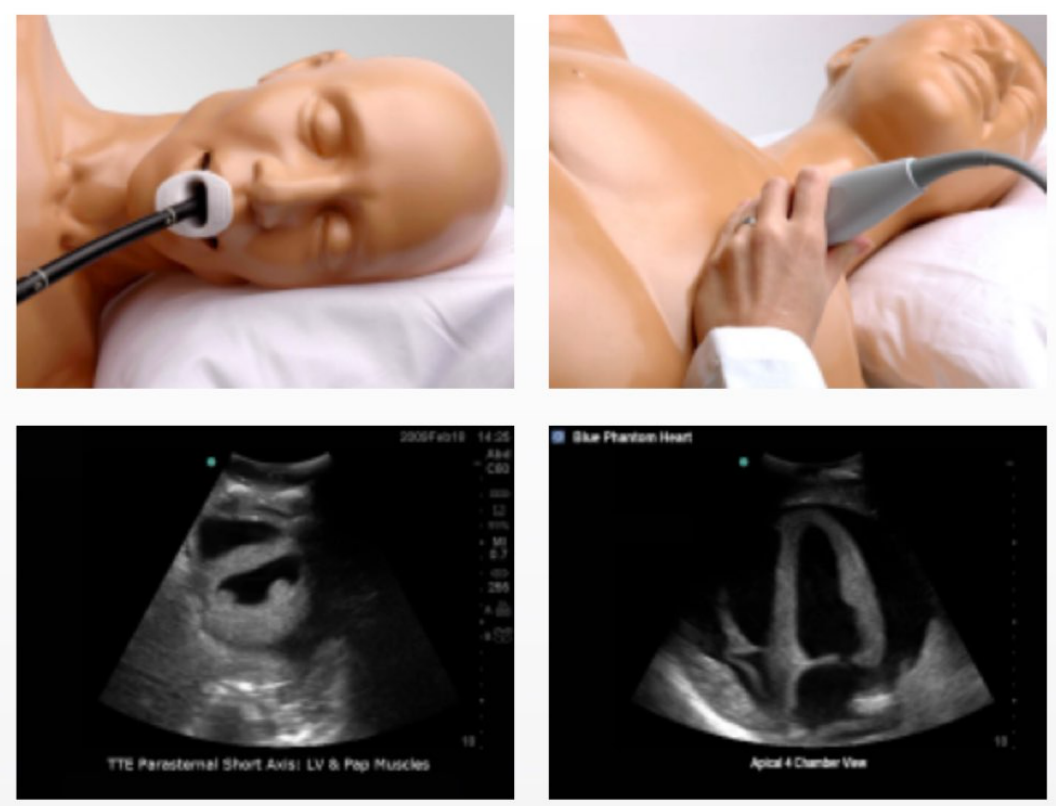

Figure 6: Static commercially available echocardiography phantom (Blue Phantom, CAE, Montreal, Canada)

Dynamic heart phantoms include the moving representation of single part of the heart

(Mitral/Aortic valves) or the vascular system (Thoracic Aorta). Up to now there is no currently available moving whole heart model. These phantoms have also been named "pulse duplicators" and have been mostly used for in vitro procedural planning ${ }^{19}$ and dynamic measurements validation ${ }^{20}$ but do not allow at the current state, to train on basic TEE image acquisition.

\subsection{D Heart Printing}

3D printing technologies have been developed to allow creation of custom parts for many different purposes. For a number of years, 3D printers were only available for industrial use, they were very bulky and expensive (in the order of $>100,000$ Euro). In the last few years desktop-size low-cost (in the order of few thousand Euro) 3D printers have been introduced to the market, allowing the further spread of this technology.

The use of 3D printing in medicine has found many areas of application, from procedural planning, to tissue engineering ${ }^{21}$. The complexity of cardiac anatomy benefitted from many successful applications of 3D printing ${ }^{22,23}$. 
In this field 3D printing has been successfully used in a wide variety of applications. It proved very effective in planning structural heart interventions ${ }^{24}$ where $3 \mathrm{D}$ printed models have been used to better understand the three dimensional anatomy and to create high fidelity custommade fluid dynamic models that allowed in vitro simulation of specific procedures ${ }^{25}$. Congenital heart disease has also greatly benefitted from 3D printing for understanding and teaching complex anatomy and to train surgeon on realistic flexible models ${ }^{26,27}$.

However in adult cardiac surgery, the use of 3D printing is limited to a few case series and report in the pre-procedural planning and training for minimally invasive surgery ${ }^{28,29}$.

Finally 3D printing has been reported in basic science research for the generation of cells scaffolding to shape cardiac and valve tissues ${ }^{30}$. This latest application is also known as "bioprinting" 31 and has the potential to allow development of biocompatible bespoke cardiac valves.

Desktop 3D printers rely on two different technologies: fused deposition modelling (Fig. 7) and stereolithography (Fig. 8).
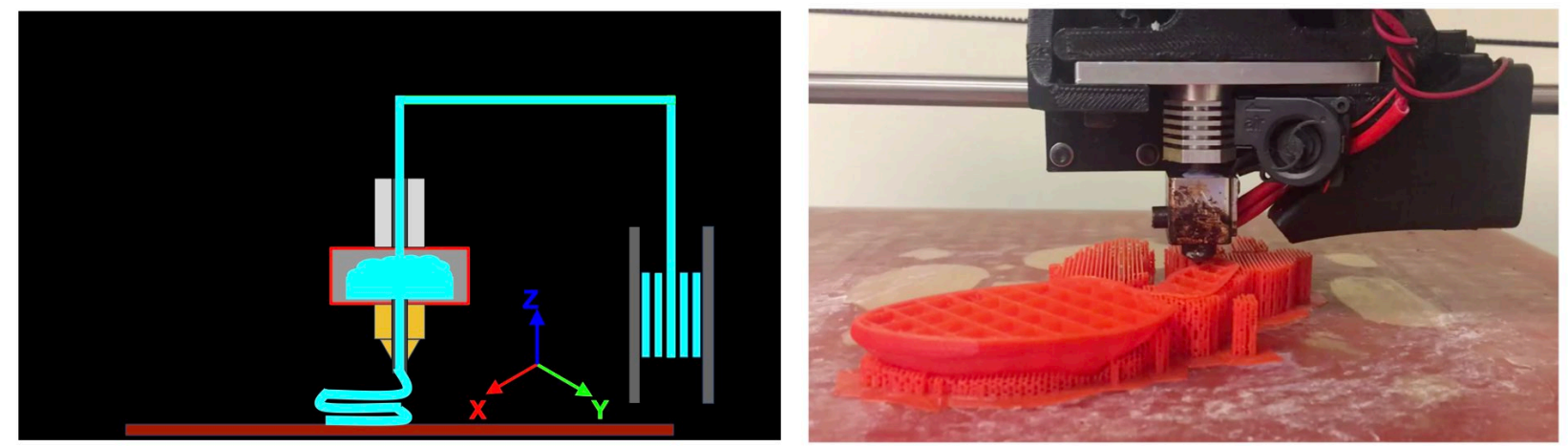

Figure 7: Fused deposition modelling: left is a diagram of the printer head that moves in three planes to depose the extruded semiliquid material on a still surface. Right is a real print of a heart using PLA filament. 

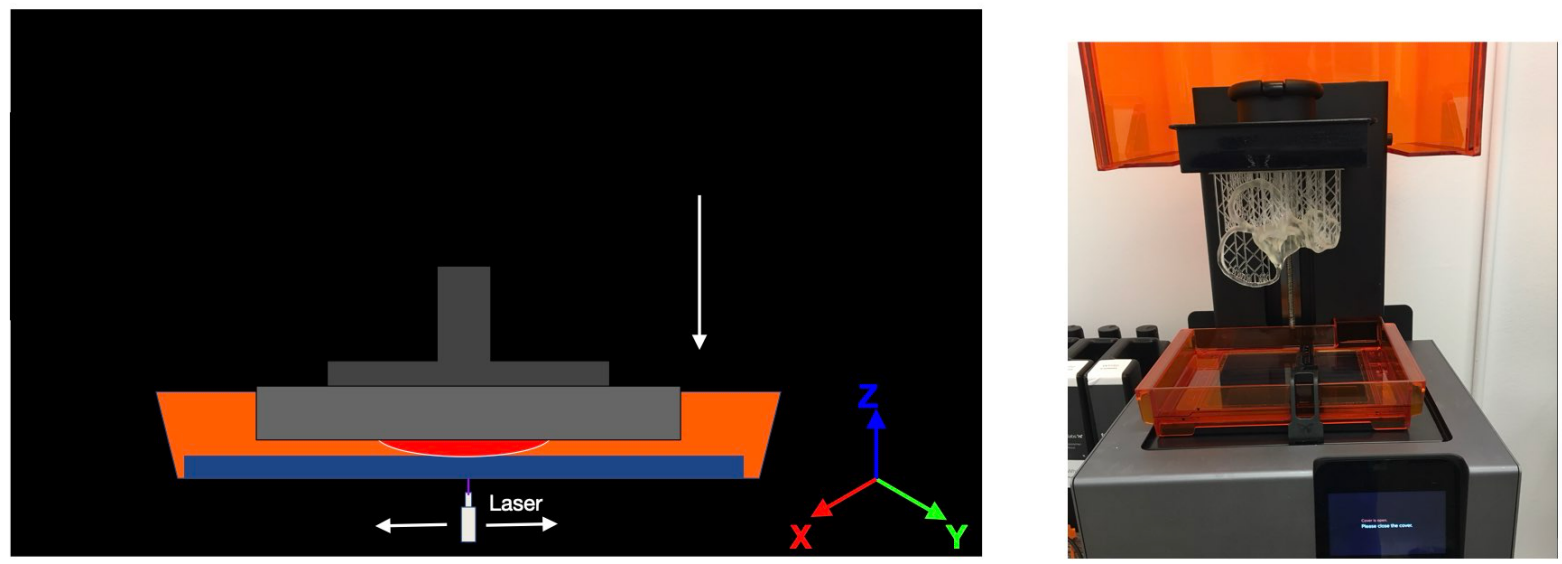

Figure 8: Stereolithography printing. Left is a diagram of the printer's resin bath with the building plate submerged in it. The laser beam is directed in several directions and solidifies a thin resin layer on the submerged building plate. Right a completed print still attached to the plate and upside-down.

With fused-deposition modelling, a meltable filament is loaded in a heated printer head where it gets melted and extruded at a constant rate and laid in a thin layer on a plate. The plate and the printer's head move independently and allow to design complex geometry with a very high precision. The typical and most affordable 3D printer's filaments are Polylactic Acid (PLA) which solidify into a rigid durable plastic. More and more materials have become available including some mimicking wood and metal. Softer materials are still unfortunately lacking therefore to create soft models we still rely on printing a rigid mold to shape a flexible object with a second moldable material (such as silicone or gel).

Stereolithography technology is based on solidification of liquid resins. The printing process also utilizes a printing plate but instead of being used a base for the print, it is submersed in the resin and the print is generated upside-down. A laser beam is directed to trigger the solidification of the resin and create a thin solid layer. Most resins are quite expensive and may require further cure under Ultraviolet light and fixation in Ethylic alcohol. Resins come in a limited choice of colors compered to filaments but they typically generate a $3 \mathrm{D}$ print that appear like transparent semi-opaque glass. Two or three different flexibilities are commonly 
available. A special solid white resin is also approved for being sterilized and used on the surgical field as tools or models. ${ }^{32}$

\subsection{D Segmentation}

The first step to $3 \mathrm{D}$ printing is $3 \mathrm{D}$ segmentation ${ }^{33}$. Segmentation extracts spatial data on a series of layers to generate a 3D object. Segmentation can be performed on anatomical data obtained with Cardiac Tomography, Magnetic Resonance Tomography and 3D echocardiography. 3D scans are saved as Digital Imaging and Communications in Medicine the chest. Segmentation process allows to select one of more tissues and extract their 3D shape. For example, one can identify the myocardial tissue to obtain a model of the ventricular walls or the blood to obtain a cast of the cardiac chambers. The segmentation process can be manually done by tracing on each CT slice the edges of a specific tissue of interest or automatically by choosing a specific tissue density to be traced by the software. Automatic segmentation is usually effective and successful whenever a specific tissue is well differentiated from the surrounding (bone vs. muscles or blood vs myocardial and muscles specially when contrast is used). Automatic segmentation is not always precise and may requires manual control. Manual segmentation is extremely time consuming, but it is necessary when the tissue to be segmented has very similar density from adjacent ones (for example valves from myocardium or vessel from surrounding tissues). Segmentation can be performed by importing a DICOM dataset into a special segmentation software. There are currently a number of segmentation software both free (3D Slicr ${ }^{\mathrm{TM}}$, Osyrix lite ${ }^{\mathrm{TM}}$ ) as well as a commercially (Mimics ${ }^{\mathrm{TM}}$ available. Their performance seems to be comparable ${ }^{33}$. They all generate a stereolithography file (.stl) that can be viewed as a three-dimensional object, grabbed and rotated in 3D space on a computer screen in a virtual reality environment, further manipulated and 3D printed. 
Automated and semi segmentation with the option of exporting .stl files has been lately integrated in commercially available 3D analytical software for the manipulation of 3D TEE and CT/MRI data.

\subsection{Development of the study phantom}

The 3D printed phantom was developed on a de-identified cardiac CT dataset obtained from an online DICOM repository (OsiriX, Pixmeo SARL, Bernex, Switzerland). The heart was segmented using the powerful open-source segmentation tools 3D Slicer (Brigham and Women's Hospital and Slicer Contributors, Boston MA. USA; http://www.slicer.org) ${ }^{34}$ and ITK-SNAP (University of Pennsylvania, Philadelphia, PA, USA; http://www.itksnap.org) ${ }^{26}$. The resulting 3D model was edited and prepared for 3D printing using Meshmixer software ${ }^{\mathrm{TM}}$ (Autodesk, San Rafael, CA, USA). The 3D heart model was transformed into two shell which were printed on a Taz Lulzbot 5 printer $^{\mathrm{TM}}$ (Aleph Object, Loveland, CO, USA) using plasticized copolyamide thermoplastic elastomer (PCTPE). This filament was chosen due to pliability and temperature stability in molten gel. The printed shells of the heart were subsequently submerged in liquefied ballistic gel (Clear Ballistics, Greenville, SC, USA). Upon gel solidification and cooling, PCTPE was manually removed leaving the two echogenic phantom heart that were then joined after air warming of the surfaces (Fig. 9). 

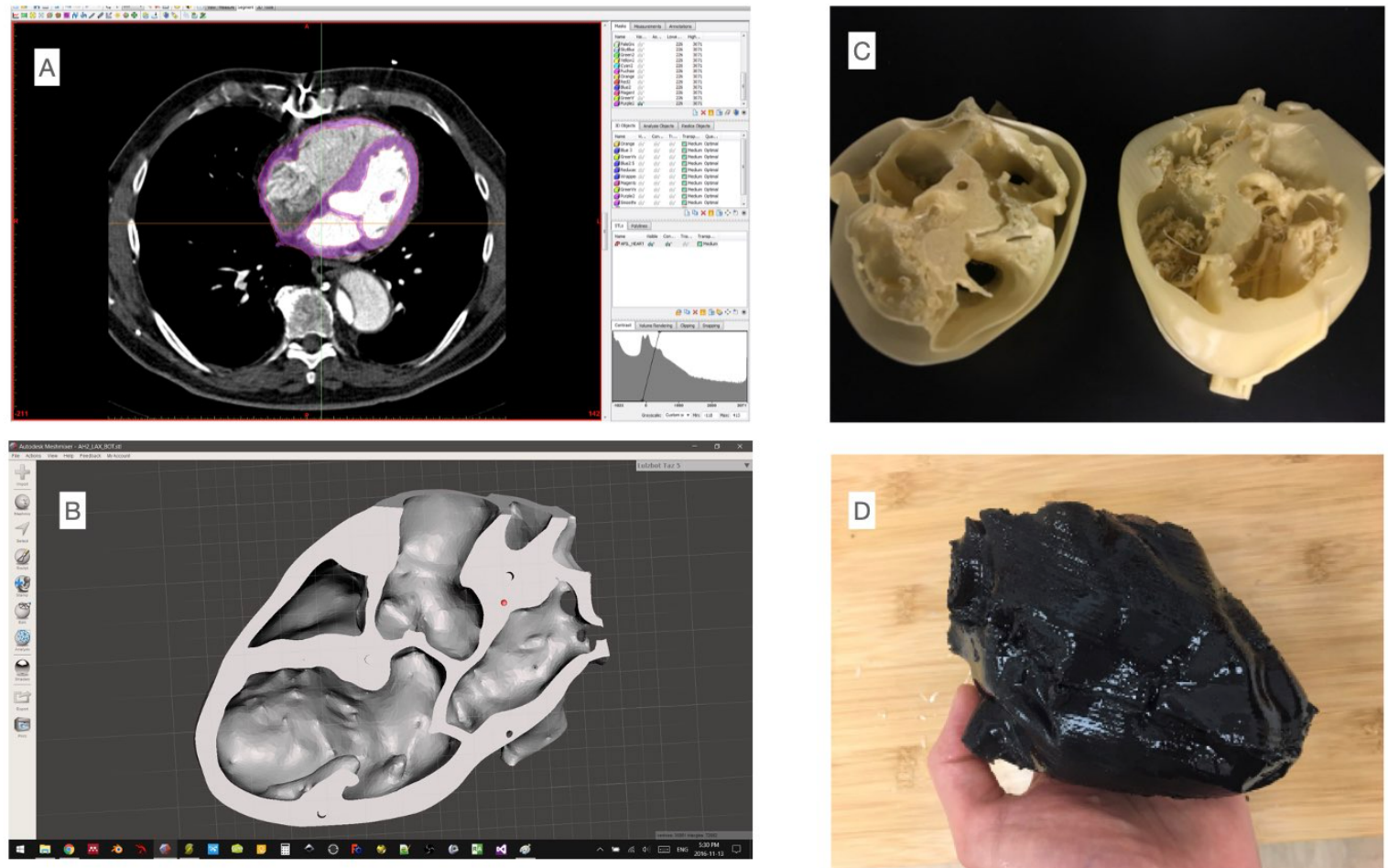

Figure 9: Steps needed to build the 3D ultrasound heart phantom. A: segmentation from CT; B: 3D modelling;

C: Print of the casts to be submerged in liquified ballistic gel; D: Final ballistic gel/graphite model.

The phantom heart was placed into a 3D printed holder into the simulator box filled with water. The holding box was designed using Meshmixer software ${ }^{\mathrm{TM}}$ (Autodesk, San Rafael, CA, USA) and printed using PLA Filament. It comprised of a heart holder, a submersion chamber with a cover and a scanning funneled channel to mimic the esophagus. The submersion chamber was then coated with a layer of silicone to make it watertight.

Detailed documentation and technical files for reproduction of the phantom are available at:

\section{https://github.com/tgh-apil/TEE-Phantom}

\subsection{Study Rationale}

In our study, we tested the use of freeware software and low-cost desktop 3D printing to develop a workflow to produce a patient-specific transesophageal echocardiographic 
phantom. This would allow production of an echocardiographic phantom from any CT or MRI file at low cost that could be used for training and potentially for procedural planning. We aimed at evaluating the reliability and usability of the low-cost phantom in comparison to a commercially available one. Reliability was defined as the quality of the image generated with the phantom. Prerecorded images of basic standard views obtained from both phantoms were blindly rated by expert echocardiographers who also had to name the view. Ease of use was assessed by asking the study participants to perform a basic standard TEE examination on both phantoms using the same commercially available echocardiographic system. We chose as objective measures the time needed to complete the examination, whether the participants were able or not to obtain each single view. Finally, we asked the participants to rate several aspects of their experience using the phantom. 


\title{
3. Publication
}

Journal of Cardiothoracic and Vascular Anesthesia 35 (2021) 208-21.5

\begin{tabular}{ccc}
\hline Contents lists available at ScienceDirect & Journal of Cardiothoracic and Vascular Anesthesia \\
ELSEVIER & journal homepage: www.jcvaonline.com \\
\hline
\end{tabular}

Original Article

Evaluation of a Patient-Specific, Low-Cost, 3-Dimensional-Printed Transesophageal Echocardiography Human Heart Phantom

\author{
Massimiliano Meineri, MD, FASE, , Joshua Qua-Hiansen, MSc ${ }^{\dagger}$, \\ Jacobo Moreno Garijo, MD ${ }^{\dagger, \ddagger}$, Bilal Ansari, MD, FRCPC ${ }^{\dagger, \ddagger}$, \\ Giulia Maria Ruggeri, $\mathrm{MD}^{\dagger}$, Joerg Ender, $\mathrm{MD}, \mathrm{PhD}^{*}$, \\ Azad Mashari, MD, FRCPC ${ }^{\dagger}$, \\ "Department of Anesthesiology and Intensive Care, Herzzentrum Leipzig, Leipzig, Germany \\ ${ }^{\dagger}$ Department of Anesthesiology and Pain Management, Toronto General Hospital, University Health Network, \\ Toronto, Ontario, Canada \\ ${ }^{\ddagger}$ Department of Anesthesiology and Pain Medicine, University of Toronto, Toronto, Ontario, Canada
}

\begin{abstract}
Objective: Currently available 3-dimensional (3D) modeling and printing techniques allow for the creation of patient-specific models based on 3D medical imaging data. The authors hypothesized that a low-cost, patient-specific, cardiac computed tomography-based phantom, created using desktop 3D printing and casting, would have comparable image quality, accuracy, and usability to an existing commercially available echocardiographic phantom.

Design: Blinded comparative study.

Setting: Simulation laboratory at a single academic institution.

Participants: Voluntary cardiac anesthesiologists at a single academic institution.

Interventions: Stage 1 of the study consisted of an online questionnaire in which a set of basic transesophageal echocardiography (TEE) views obtained from the 3D printed phantom and commercial phantom were presented to participants, who had to identify the views and evaluate their fidelity to clinical images on a Likert scale. In stage 2, participants performed an unblinded basic TEE examination on both phantoms.

Measurements and Main Results: The time needed to acquire each basic view was recorded. Overall usability of the phantoms was assessed through a questionnaire. The participants could recognize most of the views. Fidelity ratings for both phantoms were similar $(\mathrm{p}<0.05)$, with the exception of a midesophageal 2-chamber view that was observed better on the 3D printed phantom. The time required to obtain the views was shorter for the 3D printed phantom, although not statistically significant for most views. The overall user experience was better for the 3D phantom for all categories examined $(\mathrm{p}<0.05)$.

Conclusions: The study suggested that a 3D-printed TEE phantom is comparable with the commercially available one with good usability. (c) 2020 Elsevier Inc. All rights reserved.
\end{abstract}

Key Words: Transesophageal echocardiography; medical education; simulation; 3-dimensional printing

TRANSESOPHAGEAL echocardiography (TEE) has become a standard of care in cardiac operating rooms. ${ }^{1}$ This involves a comprehensive TEE examination, which mandates

${ }^{1}$ Address reprint requests to Massimiliano Meineri, MD, FASE, Department of Anesthesiology and Intensive Care, Herzzentrum Leipzig, Struempell Strasse 39, 04229 Leipzig, Germany.

E-mail address: Massimiliano.Meineri@medizin.uni-leipzig.de (M. Meineri). training in advanced perioperative TEE, typically achieved during cardiac anesthesia fellowship training. Basic and focused TEE examinations comprise a simplified examination, including a limited number of views to assess a patient's anatomy, pathology, and hemodynamic status and to guide clinical management. ${ }^{2,3}$ Simplified TEE examinations have become a very valuable tool in noncardiac surgery, emergency medicine, and intensive care settings and has driven the increasing

https://doi.org/10.1053/j.jvca.2020.07.008

$1053-0770 / \odot 2020$ Elsevier Inc. All rights reserved 
demand for TEE training outside of cardiac anesthesia. ${ }^{4-6}$ The aim of TEE training is acquisition of knowledge and skills such as understanding 3-dimensional (3D) cardiac anatomy, image interpretation, probe manipulation, and image optimization.

Simulation-based education has been shown to increase the task-specific capability of medical trainees similarly, and TEE training greatly benefits from the use of simulators. ${ }^{7-10}$ Echocardiography simulators allow for real-time scanning and generate ultrasound images that can be displayed side by side with high-fidelity virtual anatomic models. ${ }^{10}$ Virtual reality also has been integrated recently to further enhance the learning experience. ${ }^{11}$ Practice on TEE simulators significantly shortens the learning curve to acquire TEE views, thus limiting the need for practicing on real patients. ${ }^{12,13}$

Modern tangible simulators come in the following 2 general varieties: computer-assisted simulators and physical phantoms. Computer-assisted simulators consist of mannequins with sophisticated magnetic tracking systems that detect the position of a mock TEE probe. A computer workstation then generates a simulated, moving slice image based on an artificial 3D animated model of the heart. In the authors' experience, these devices are very expensive and have many limitations. First, they do not integrate the interface of a real echocardiography machine and therefore do not allow trainees to familiarize themselves with knob function and image optimization. Second, the images, although generally accurate in terms of morphology, are computer generated and are not comparable with images obtained in a clinical setting. Finally, they offer a limited number of pathologies that typically must be purchased in packages for added cost.

Echocardiography phantoms consist of an echogenic sculpted heart model in a mannequin or a holding device. They have the advantage of allowing image acquisition using any clinical ultrasound system, are portable, do not require power supply, require minimal maintenance, and are very durable. The use of a real ultrasound system allows trainees to familiarize themselves with real knobs and user interface. The image generated depends on the same rules of ultrasound physics as in real patients. Phantoms can be static or dynamic. Most dynamic heart phantoms, although customizable to patient- specific pathology, reproduce only some of the cardiac chambers and not the entire heart. ${ }^{14,15}$ Currently available wholeheart phantoms are static models. Most of them reproduce an artificially sculpted heart model, capturing normal anatomy. They do not replicate pathologic anatomy and, while they are significantly less expensive than computer-assisted simulators, they typically cost in excess of $\$ 2,000$.

Three-dimensional modeling and printing technologies have enabled the creation of patient-specific phantoms capable of being used as task-trainers. ${ }^{16-22}$ Low-cost $3 \mathrm{D}$ printers, especially when combined with widely available open- source 3D segmentation and modeling software, have enabled an increasing number of end-users to use this technology for medical education and procedural training. . $^{23,24}$

The present study aimed to compare the ease of use and accuracy of a low-cost, patient-specific, cardiac computed tomography (CT)-based, 3D-printed, echogenic TEE phantom compared with a commercially available echocardiography training phantom. The study hypothesis was that such patient-specific phantoms would have non-inferior image quality, accuracy, and usability to existing commercially available phantoms at a fraction of the cost.

\section{Methods}

After Institutional Research Ethics Board approval, a blinded comparative study between a low-cost, 3D-printed, echogenic cardiac phantom and a commercially available model (Blue Phantom TEE; CAE, Montreal, QC, Canada) was conducted. The primary aim of the study was to evaluate and compare anatomic accuracy and image quality of standard TEE views on both phantoms.

The secondary aim was to determine the ease of use of the 3D-printed phantom compared with a standard commercial phantom (Fig 1) by measuring the time taken to obtain each basic TEE view and collect users' qualitative feedback.

To develop the 3D-printed phantom, a deidentified cardiac CT data set was obtained from an online DICOM repository (OsiriX; Pixmeo SARL, Bernex, Switzerland). The heart was segmented using the open- source tool ITK SNAP (University of Pennsylvania, Philadelphia, PA). ${ }^{25}$ The resulting 3D model
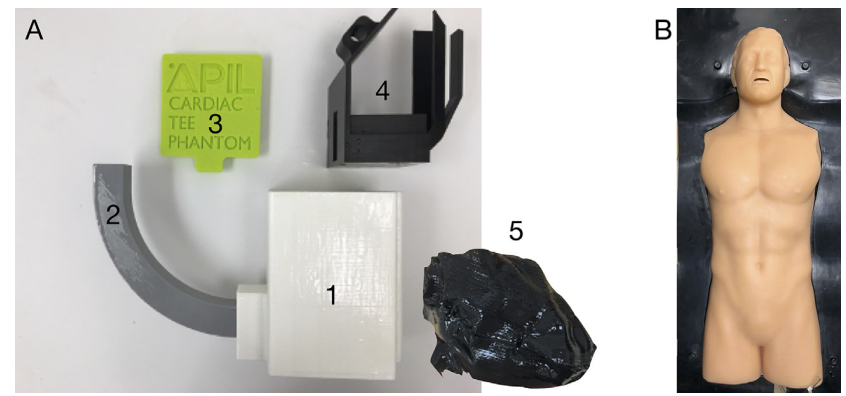

Fig 1. (A) Three-dimensional-printed transesophageal echocardiography phantom. 1, box; 2, funneled probe's channel; 3, cover of box; 4, heart holder; 5, gel heart. (B) Commercial transesophageal echocardiography phantom (Blue Phantom TEE; CAE, Montreal, QC, Canada). 

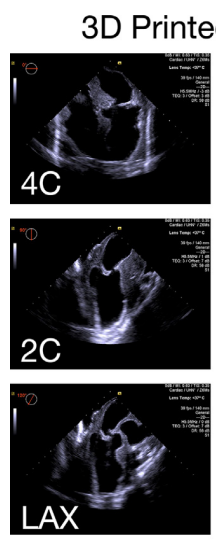
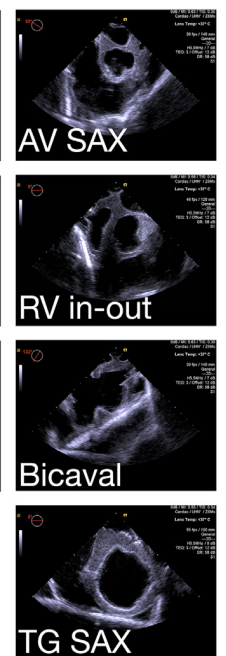

Blue phantom
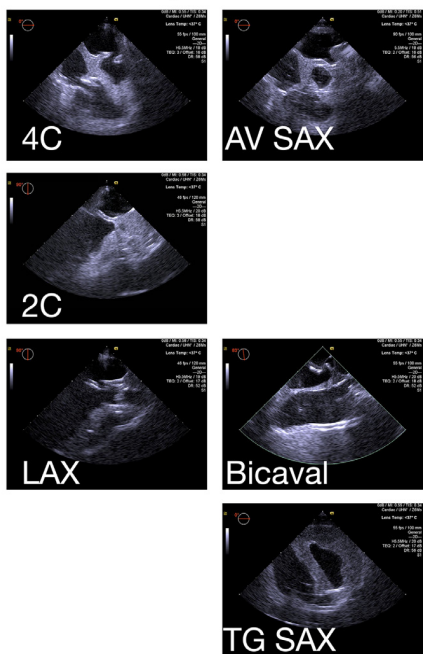

Fig 2. Set of images used for the online test. Blue Phantom is the commercially available phantom. 2C, midesophageal 2-chamber view; 4C, midesophageal 4chamber view; AV SAX, midesophageal aortic valve short-axis view; bicaval, midesophageal bicaval view; LAX, midesophageal long-axis view; RV in-out, midesophageal right ventricular inflow-outflow view; TG SAX, transgastric short-axis view.

was edited and prepared for 3D printing using Meshmixer software (Autodesk, San Rafael, CA). The 3D heart model was transformed into a shell that was printed on a Lulzbot TAZ 5 printer (Fargo Additive Manufacturing Equipment 3D, Fargo, ND) using plasticized copolyamide thermoplastic elastomer. This filament was chosen due to pliability and temperature stability in molten gel (see later). Printed shells of the heart were submerged in liquefied ballistic gel (Clear Ballistics, Greenville, SC). Upon gel solidification, the plasticized copolyamide thermoplastic elastomer was removed, leaving an echogenic phantom heart (see Fig 1, A). The phantom heart was placed into a $3 \mathrm{D}$ printed holder into the simulator box and filled with water. Detailed documentation and technical files for reproduction of the phantom are available at https://github.com/tghapil/TEE-Phantom.

The holding box was designed using Meshmixer software and printed using Polylactic Acid (PLA) filament. It comprises a heart holder, a submersion chamber with a cover, and a scanning funneled channel to mimic the esophagus (see Fig 1, A). The submersion chamber then was coated with a layer of silicone to make it watertight.

Ten cardiac anesthesiologists from the authors' institution, with expert knowledge in TEE examinations and certification in advanced perioperative echocardiography (National Board of Echocardiography, Raleigh, NC), were recruited for the study. None of the recruited staff was involved in the development of the phantom. The study inclusion criteria required that the participants were naïve to either phantom type. All signed a written informed consent.

The study was divided into 2 stages. Stage 1 consisted of image assessment. A set of basic TEE views was obtained by the primary investigator (M.M.) on both phantoms using a Siemens ACUSON SC 2200 System and a Z6Ms TEE transducer (Siemens, Mountain View, CA). The following 7 views were obtained: midesophageal 4- chamber (4C), midesophageal 2chamber (2C), midesophageal bicaval, long-axis (LAX), midesophageal aortic valve short-axis (AV SAX), midesophageal right ventricular inflow-outflow (RV in-out), and transgastric short-axis. These were chosen because with the addition of views from the descending aorta and the aortic arch (not reproduced in the phantom), they constitute a basic TEE examination. ${ }^{2}$ Each view was saved without any image identifier pictured (.bmp at $400 \mathrm{ppi}$ ) and loaded in random order into an online questionnaire (Fig 2). After agreeing to be part of the study, the participants were given access to the questionnaire via e-mail. They had a maximum of 30 minutes to complete the survey, and they could not review the questions after answers were submitted but could decide when to move forward. The questionnaire was to be completed before the second, hands-on, part of the study. For each image, participants were asked the following 2 questions: (1) which TEE view is being presented, and (2) on a Likert scale of 1 to 5, please indicate the quality of the image being presented with a score of " 5 " as "realistic to patient views" and a score of " 1 " as "not at all realistic to patient views."

In stage 2 of the study, participants were asked to perform a basic TEE examination (with the exception of the views of the aorta) in the simulation laboratory on the 3D-printed and the commercial phantom and obtain the following views in the following sequence: 4C, 2C, bicaval, LAX, AV SAX, RV in-out, and transgastric short-axis. The examinations were performed using a Siemens ACUSON SC 2200 System and a Z6Ms TEE 
transducer, and all study participants were familiar with this equipment. Participants were randomly assigned as to which simulator/phantom would be used first. Each participant was given a maximum of 30 minutes per phantom. The time taken from probe insertion to the first view and between views was recorded and rounded to the nearest second. Each view, once obtained, was recorded as a 2 -second loop, to be assessed at a later stage for accuracy.

The phantoms' overall usability was assessed with a questionnaire that was completed on paper immediately after the end of the second TEE examination.

For each phantom, the following questions were asked and graded on a 1-to-5 Likert scale, for which 1 was the lowest and 5 was the highest score:

1. What was the ease to obtain standard views?

2. How did the probe manipulation compare with a real patient?

3. How did the image quality compare with a real patient?

For all variables, the median and interquartile range were calculated. Wilcoxon signed-rank test was used to assess significant differences in all variables while not normally distributed.

\section{Results}

All 10 participants completed all parts of the study. For the online questionnaire, the RV in-out view from the commercial phantom was excluded because it was considered only partially representative of the clinical view and too difficult to recognize.

The results of the online test are summarized in Tables 1 and 2. All the views could be identified correctly by more than two-thirds of the participants, with the exception of the bicaval and the AV SAX views on the 3D-printed phantom; these views were recognized by fewer than half the participants. The global average Likert scale score was between 2 and 3 for the 3D-printed phantom and between 2 and 4 for the commercial phantom, with no significant differences in the scores for

Table 1

Correctly Identified Views

\begin{tabular}{lll}
\hline & 3D-Printed Phantom & Commercial Phantom \\
\hline ME RV in-out & 90 & \\
ME AV SAX & 40 & 70 \\
ME 4C & 100 & 100 \\
ME 2C & 100 & 90 \\
TG SAX & 100 & 80 \\
ME bicaval & 30 & 100 \\
ME LAX & 100 & 80 \\
\hline
\end{tabular}

NOTE. Results are expressed as percentage of correct answers. Abbreviations: ME 2C, midesophageal 2-chamber view; ME 4C, midesophageal 4-chamber view; ME AV SAX, midesophageal aortic valve short-axis view; ME bicaval, midesophageal bicaval view; ME LAX, midesophageal long-axis view; ME RV in-out, midesophageal inflow-outflow view; TG SAX, transgastric mid-left ventricular short-axis view.
Table 2

Rating of Each View Proposed Compared With the Same View From a Human Subject on a Likert Scale

\begin{tabular}{llll}
\hline & 3D-Printed Phantom & Commercial Phantom & $p$ \\
\hline ME AV SAX & $2(1.5)$ & $2(1)$ & NS \\
ME 4C & $3(1.5)$ & $2(1)$ & NS \\
ME 2C & $3(0.75)$ & $3(1.5)$ & $<0.05$ \\
TG SAX & $2(1)$ & $3(0.75)$ & NS \\
ME bicaval & $2(0)$ & $2(1)$ & NS \\
ME LAX & $3(0)$ & $4(1)$ & NS
\end{tabular}

NOTE. Results are expressed as percentage of correct answers or as median and interquartile range. Wilcoxon signed-rank test was performed. Significance was considered for $\mathrm{p}<0.05$

Abbreviations: ME 2C, midesophageal 2-chamber view; ME 4C midesophageal 4-chamber view; ME AV SAX, midesophageal aortic valve short-axis view; ME bicaval, midesophageal bicaval view; ME LAX, midesophageal long-axis view; ME RV in-out, midesophageal inflow-outflow view; TG SAX, transgastric mid-left ventricular short-axis view.

$* 1=$ not comparable with the equivalent view obtained on a human subject; $5=$ equivalent to the view obtained on a human subject.

single views except for the $2 \mathrm{C}$ view, which was reported as being better with the 3D-printed phantom (see Table 2).

During the second part of the study, half the participants performed the basic TEE examination first on the 3D-printed phantom and the other half first on the commercial phantom. All participants could obtain all views. Clips were saved for post-study review, and all were deemed acceptable by 2 TEE experts (M.M. and A.M.).

The times to obtain each view are summarized in Table 3 and Fig 3. On average, they were shorter for the 3D-printed phantom and reached statistical significance for the $4 \mathrm{C}, 2 \mathrm{C}$, LAX, and RV in-out views.

Table 3

Time in Seconds Required to Obtain a View From Insertion of the Probe or From the Last Acquired Image

\begin{tabular}{llll}
\hline & $\begin{array}{l}\text { 3D-Printed } \\
\text { Phantom }\end{array}$ & $\begin{array}{l}\text { Commercial } \\
\text { Phantom }\end{array}$ & $p$ \\
\hline Insert to ME4C & $26.22(26.22)$ & $42.28(58.19)$ & NS \\
ME4C-ME2C & $10.72(11.06)$ & $27.63(17.49)$ & NS \\
$\begin{array}{l}\text { ME2C-ME LAX } \\
\text { ME LAX-ME AV }\end{array}$ & $\begin{array}{l}18.31(14.17) \\
\quad \text { SAX }\end{array}$ & $14.15(18.26)$ & NS \\
$\begin{array}{l}\text { ME AV SAX-ME } \\
\quad \text { RV in-out }\end{array}$ & $12.89(5.89)$ & $54.3(42.28)$ & $<0.05$ \\
$\begin{array}{l}\text { ME RV in- } \\
\text { out-ME bicaval }\end{array}$ & $31.6(21.18)$ & $57.41(22.79)$ & NS \\
$\begin{array}{l}\text { ME bicaval-TG } \\
\text { SAX }\end{array}$ & $16.53(9.11)$ & $19.73(6.46)$ & NS \\
\end{tabular}

NOTE. Results expressed as median and interquartile range. Wilcoxon signedrank test was performed. Significance was considered for $\mathrm{p}<0.05$. Abbreviations: ME 2C, midesophageal 2-chamber view; ME 4C, midesophageal 4-chamber view; ME AV SAX, midesophageal aortic valve short-axis view; ME bicaval, midesophageal bicaval view; ME LAX, midesophageal long-axis view; ME RV in-out, midesophageal inflow-outflow view; TG SAX, transgastric mid-left ventricular short-axis view. 


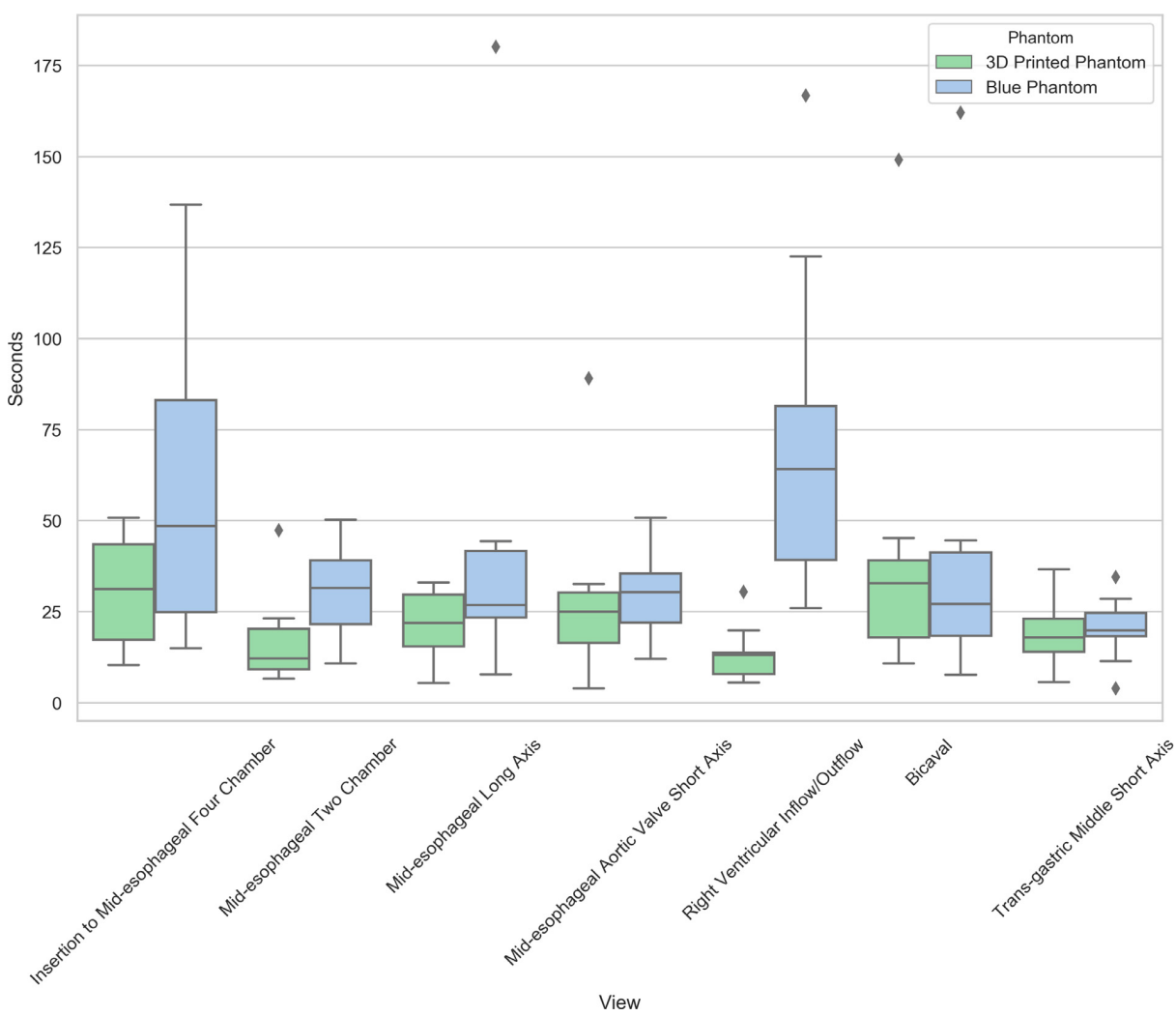

Fig 3. Time in seconds required to obtain a view from insertion of the probe or from the last acquired image. Blue Phantom is the commercially available phantom. The middle line indicates the median, the box indicates the interquartile range, the columns indicate the mean, and the bard the higher and lower values. The diamonds identify outlier values.

The results of the post-study user questionnaire are summarized in Table 4 and Fig 4 and were overall in favor of the 3Dprinted phantom.

Table 4

Usability Questionnaire With Results on a Likert Scale ${ }^{*}$

\begin{tabular}{llll}
\hline & $\begin{array}{l}\text { 3D-Printed } \\
\text { Phantom }\end{array}$ & $\begin{array}{l}\text { Commercial } \\
\text { Phantom }\end{array}$ & $p$ \\
\hline $\begin{array}{l}\text { Ease of obtaining } \\
\text { views }\end{array}$ & $4(1)$ & $2(0)$ & $<0.05$ \\
$\begin{array}{l}\text { Probe } \\
\text { manipulation }\end{array}$ & $4(1)$ & $3(1.75)$ & $<0.05$ \\
$\quad \begin{array}{l}\text { accuracy } \\
\text { Image quality }\end{array}$ & $3(1)$ & $1(0.75)$ & $<0.05$ \\
$\begin{array}{l}\text { Overall } \\
\text { experience }\end{array}$ & $3(1)$ & $2(1.75)$ & $<0.05$ \\
\end{tabular}

NOTE. Results are expressed as median and interquartile range. Wilcoxon signed-rank test was performed. Significance was considered for $p<0.05$.

$* 1$ is the lowest score, and 5 is the highest score.

\section{Discussion}

The fidelity to clinical views obtained with a standard echocardiographic system was rated similarly for the 2 phantoms, with the exception of $2 \mathrm{C}$ views. The users were able to obtain the same standard TEE views on the experimental phantom that were obtained on a commercial phantom. A basic TEE examination could be performed in less time on the 3D-printed phantom, which received significantly better feedback from the users for all categories of user experience $(p<0.05)$. This suggested that a 3D-printed TEE phantom could be used with a standard echocardiographic system in basic TEE training.

The difference in time to perform a basic examination, although not significant for most views, on the 2 phantoms may be explained by the ease of movement of the TEE probe in the 3D-printed phantom because it is floating in water compared with the tight silicon esophagus in the commercial phantom. It also could be explained by the ease of obtaining the views and echogenicity of the phantom. Even though the commercial phantom could simulate pericardial effusion and be 


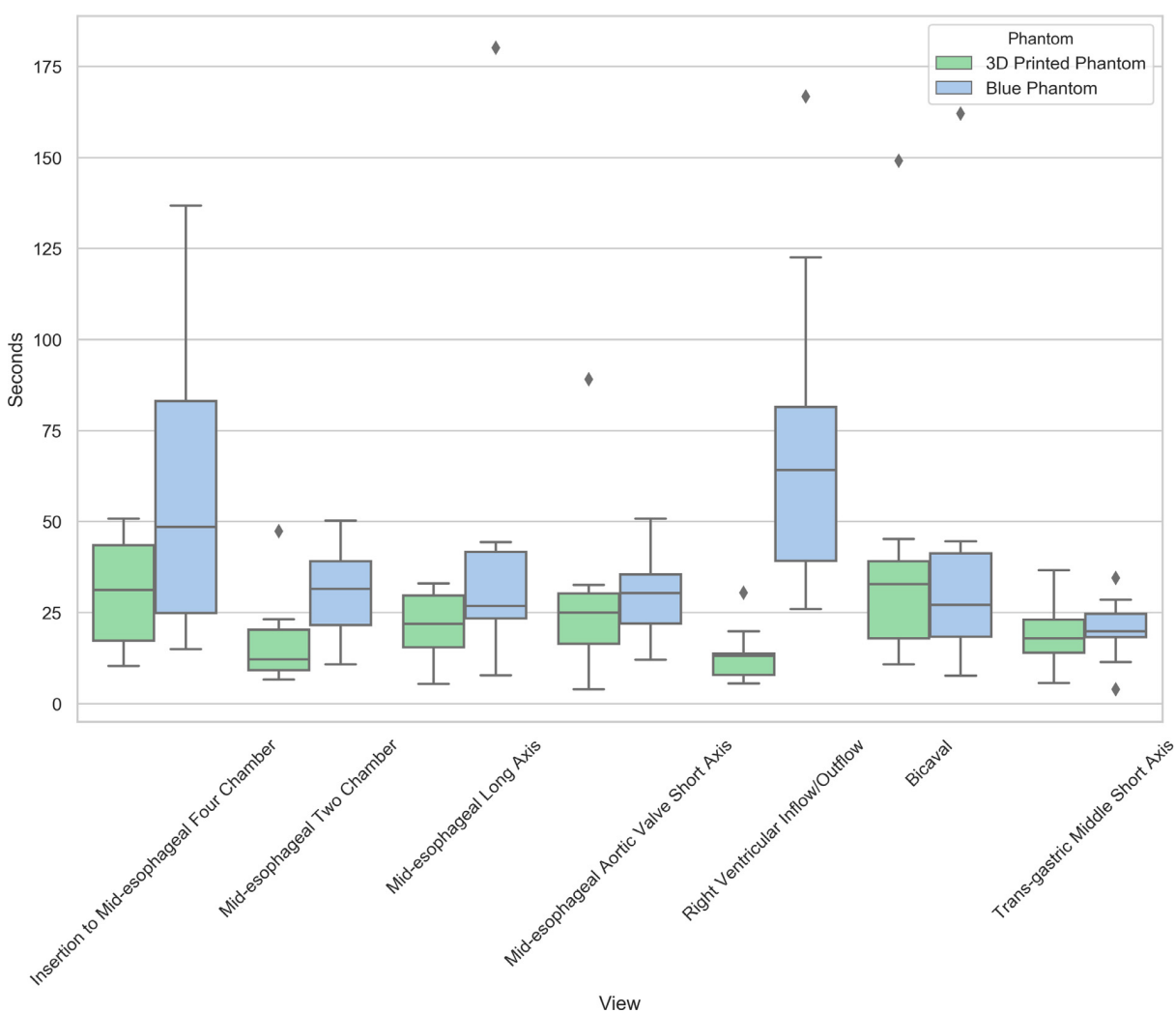

Fig 3. Time in seconds required to obtain a view from insertion of the probe or from the last acquired image. Blue Phantom is the commercially available phantom. The middle line indicates the median, the box indicates the interquartile range, the columns indicate the mean, and the bard the higher and lower values. The diamonds identify outlier values.

The results of the post-study user questionnaire are summarized in Table 4 and Fig 4 and were overall in favor of the 3Dprinted phantom.

Table 4

Usability Questionnaire With Results on a Likert Scale ${ }^{*}$

\begin{tabular}{llll}
\hline & $\begin{array}{l}\text { 3D-Printed } \\
\text { Phantom }\end{array}$ & $\begin{array}{l}\text { Commercial } \\
\text { Phantom }\end{array}$ & $p$ \\
\hline $\begin{array}{l}\text { Ease of obtaining } \\
\text { views }\end{array}$ & $4(1)$ & $2(0)$ & $<0.05$ \\
$\begin{array}{l}\text { Probe } \\
\text { manipulation }\end{array}$ & $4(1)$ & $3(1.75)$ & $<0.05$ \\
$\begin{array}{l}\text { accuracy } \\
\begin{array}{l}\text { Image quality } \\
\text { Overall } \\
\text { experience }\end{array}\end{array}$ & $3(1)$ & $1(0.75)$ & $<0.05$ \\
& $3(1)$ & $2(1.75)$ & $<0.05$ \\
\hline
\end{tabular}

NOTE. Results are expressed as median and interquartile range. Wilcoxon signed-rank test was performed. Significance was considered for $p<0.05$.

$* 1$ is the lowest score, and 5 is the highest score.

\section{Discussion}

The fidelity to clinical views obtained with a standard echocardiographic system was rated similarly for the 2 phantoms, with the exception of $2 \mathrm{C}$ views. The users were able to obtain the same standard TEE views on the experimental phantom that were obtained on a commercial phantom. A basic TEE examination could be performed in less time on the 3D-printed phantom, which received significantly better feedback from the users for all categories of user experience $(p<0.05)$. This suggested that a 3D-printed TEE phantom could be used with a standard echocardiographic system in basic TEE training.

The difference in time to perform a basic examination, although not significant for most views, on the 2 phantoms may be explained by the ease of movement of the TEE probe in the 3D-printed phantom because it is floating in water compared with the tight silicon esophagus in the commercial phantom. It also could be explained by the ease of obtaining the views and echogenicity of the phantom. Even though the commercial phantom could simulate pericardial effusion and be 
Three-dimensional printing on the more affordable fused deposition modeling systems is primarily limited by unavailability of printable echogenic materials. This is balanced by far lower costs and simpler postprocessing, with a much smaller potential for hazardous exposures than is the case for more industrial printing systems. Given the lack of an echogenic material that allows for direct printing, the authors needed to look for a moldable material that had echogenic characteristics similar to that of human heart muscle. Currently available echocardiographic phantoms use Zerdine (CIRS, Norfolk, VA), a proprietary water-based polymer that is not available for purchase.

Common edible gelatin is very affordable and has excellent echogenicity, which can be modulated with the addition of graphite powder or other dispersing agents; however, it is perishable and friable. The authors therefore chose ballistic gel because it melts at a relatively low temperature $\left(90^{\circ}\right.$ centigrade) and can be prepared in a simple crockpot. Once solid, it has excellent ultrasound characteristics in water, is relatively stiff, and is very durable. It is available in a range of consistencies and can be supplemented with graphite to modulate echogenicity.

The authors' 3D ultrasound phantom can be fabricated with a total budget of approximately $\$ 150$ in materials for printing filament and ballistic gel. The production requires a variable time for CT or MRI segmentation (in the authors' case, approximately $10 \mathrm{~h}$ ), approximately 10 hours of printing time, and another 10 hours of work for casting and assembly. In a nonprofit, non-industrial environment, a single trained technician potentially can manufacture up to 4 phantoms per week. This is to be compared with the cost of a commercial phantom, which typically costs $\$ 3,000$ to $\$ 25,000$ (the current version of the model used in the present study retails for $\$ 25,500$ ). Larger centers with higher demand of models may engage in smallscale production to meet their own demands and supply. Small local companies also may collaborate with healthcare centers in manufacturing these phantoms.

The present study had a number of limitations. First, it was a single- institution study on a small convenience subject sample consisting approximately of all TEE-certified cardiac anesthesiologists who were never exposed to the phantoms. The study participants were potentially biased toward the 3D phantom because it was developed at their institution. All participants were practicing cardiac anesthesiologists, with advanced skills and a minimal number of 50 comprehensive TEE examinations per year, which limits the translatability of the usability results to less-skilled users and novices. The times to complete the basic examination were not compared with the average time taken by each subject on a real patient. In addition, only a single clinical echocardiography system was tested and only views included in the basic examination were covered and as such have not directly verified the generalizability of these results to other systems and the comprehensive TEE examination. Finally, there are inherent limitations to using Likert scales, such as providing non-normally distributed parametric data; however, their simplicity and ease of use led to their utilization in this study.

Additional studies should be performed to evaluate the usability of the phantom by TEE novices and to assess the effect of phantom training on understanding TEE image interpretation and image acquisition in real patients, especially when compared with high-fidelity simulators and traditional supervised hands-on experience. Finally, the reliability of the 3D-printed phantom should be tested for different pathologies.

\section{References}

1 Hahn RT, Abraham T, Adams MS, et al. Guidelines for performing a comprehensive transesophageal echocardiographic examination: Recommendations from the American Society of Echocardiography and the Society of Cardiovascular Anesthesiologists. J Am Soc Echocardiogr 2013;26:921-64

2 Reeves ST, Finley AC, Skubas NJ, et al. Basic perioperative transesophageal echocardiography examination: A consensus statement of the American Society of Echocardiography and the Society of Cardiovascular Anesthesiologists. J Am Soc Echocardiogr 2013;26:443-56.

3 Arntfield R, Pace J, Hewak M, et al. Focused transesophageal echocardiography by emergency physicians is feasible and clinically influential: Observational results

4 Fayad A, Shillcutt SK. Perioperative transesophageal echocardiography for non-cardiac surgery. Can J Anaesth 2018;65:381-98.

5 Garcia YA, Quintero L, Singh K, et al. Feasibility, safety, and utility of advanced critical care transesophageal echocardiography performed by pulmonary/critical ere fellows in a medical ICU. Chest 2017:152:736 41 .

6 Mayo PH, Narasimhan M, Koenig S. Critical care transesophageal echocardiography. Chest 2015;148:1323-32.

7 Rodriguez-Paz JM, Kennedy M, Salas E, et al. Beyond "see one, do one, teach one": Toward a different training paradigm. Postgrad Med 2009;85:244-9.

8 Ziv A, Ben-David S, Ziv M. Simulation based medical education: an opportunity to learn from errors. Med Teach 2005:27:193-9.

9 Ziv A, Small SD, Wolpe PR. Patient safety and simulation-based medical education. Med Teach 2000;22:489-95.

10 Bose RR, Matyal R, Warraich HJ, et al. Utility of a transesophageal echocardiographic simulator as a teaching tool. J Cardiothorac Vasc Anesth 2011;25:212-5.

11 Mahmood F, Mahmood E, Dorfman RG, et al. Augmented reality and ultrasound education: Initial experience. J Cardiothorac Vasc Anesth 2018:32:1363-7.

12 Prat G, Charron C, Repesse X, et al. The use of computerized echocardiographic simulation improves the learning curve for transesophageal hemodynamic assessment in critically ill patients. Ann Intensive Care 2016:6:27.

13 Arntfield R, Pace J, McLeod S, et al. Focused transesophageal echocardiography for emergency physicians-description and results from simulation training phy for emergency physicians-description and results from simulation
of a structured four-view examination. Crit Ultrasound J 2015;7:27.

of a structured four-view examination. Crit Ultrasound J 2015;7:27.
14 Baribeau Y, Sharkey A, Mahmood E, et al. Three-dimensional printing and 14 Baribeau Y, Sharkey A, Mahmood E, et al. Three-dimensional printing and
transesophageal echocardiographic imaging of patient-specific mitral valve models in a pulsatile phantom model. J Cardiothorac Vasc Anesth 2019;33:3469-75

15 Mashari A, Knio Z, Jeganathan J, et al. Hemodynamic testing of patientspecific mitral valves using a pulse duplicator: A clinical application of three-dimensional printing. J Cardiothorac Vasc Anesth 2016;30:1278-85. 16 Adams F, Qiu T, Mark A, et al. Soft 3D-printed phantom of the human kid ney with collecting system. Ann Biomed Eng 2017;45:963-72.

17 Carton AK, Bakic P, Ullberg C, et al. Development of a physical 3D anthropomorphic breast phantom. Med Phys 2011;38:891-6. 
18 Chao I, Young J, Coles-Black J, et al. The application of three-dimensional printing technology in anaesthesia: A systematic review. Anaesthesia 2017;72:641-50.

19 Jeganathan J, Baribeau Y, Bortman J, et al. Use of 3-dimensional printing to create patient-specific thoracic spine models as task trainers. Reg Anesth Pain Med 2017;42:469-74

20 Mashari A, Montealegre-Gallegos M, Jeganathan J, et al. Low-cost threedimensional printed phantom for neuraxial anesthesia training: Development and comparison to a commercial model. PLoS One 2018;13:e0191664.

21 West SJ, Mari JM, Khan A, et al. Development of an ultrasound phantom for spinal injections with 3-dimensional printing. Reg Anesth Pain Med 2014;39:429-33.
22 Yunker BE, Dodd GD, Chen SJ, et al. The design and fabrication of two portal vein flow phantoms by different methods. Med Phys 2014;41:023701

23 Lichtenberger JP, Tatum PS, Gada S, et al. Using 3D printing (additive manufacturing) to produce low-cost simulation models for medical training. Mil Med 2018;183(Suppl 1):73-7.

24 Meier LM, Meineri M, Qua Hiansen J, et al. Structural and congenital hear disease interventions: The role of three-dimensional printing. Neth Heart J 2017:25:65-75.

25 Yushkevich PA, Piven J, Hazlett HC, et al. User-guided 3D active contour segmentation of anatomical structures: Significantly improved efficiency and reliability. Neuroimage 2006;31:1116-28. 


\title{
4. Summary
}

Dissertation for the acquisition of the academic title of Dr. med.

\section{Evaluation of a Patient-Specific, Low-Cost, 3-Dimensional-Printed Transesophageal Echocardiography Human Heart Phantom}

\author{
Submitted by: \\ Massimiliano Meineri
}

Department of Anesthesia and Intensive Care Medicine, Herzzentrum Leipzig

\section{Supervisor:}

Prof. Dr. med. habil. Jörg Ender

Submitted in December 2020

Simulation based education has been shown to increase the task-specific capability of medical trainees. Transesophageal echocardiography training greatly benefits from the use of simulators. They allow real time scanning of a beating heart and generation of ultrasound images side by side with anatomically accurate virtual model. These simulators are costly and have many limitations. $3 \mathrm{D}$ printing technologies have enabled the creation of bespoke phantoms capable of being used as task-trainers. This study aims to compare the ease of use and accuracy of a low-cost patient-specific, Computer-tomography based, 3D printed, echogenic TEE phantom compared to a commercially available echocardiography training mannequin. 
We hypothesized that a low-cost, 3D printed custom-made, cardiac phantom has comparable image quality, accuracy and usability as existing commercially available echocardiographic phantoms.

After Institutional Ethic Research Board approval, we recruited ten American Board Certified cardiac anesthesiologists and conducted a blinded comparative study divided into two stages. Stage one consisted of image assessment. A set of basic TEE views obtained from the $3 \mathrm{D}$ printed and commercial phantom were presented to the participants on a computer screen in random order. For each image, participants will be asked to identify the view, identify the quality of the image on a 1-5 Likert scale compared to the corresponding human view and guess with which phantom it was acquired (1 not at all realistic to patients view and 5 realistic to patients view). Stage two, participants will be asked to use the 3D printed and the commercially available phantom to obtain basic TEE views. In a maximum of 30 minutes. Each view was recorded and assessed for accuracy by two certified echocardiographers. Time needed to acquire each basic view and number of correct views was recorded. Overall usability of the phantoms was assessed through a questionnaire. For all continuous variables, we will calculate mean, median and standard deviation. We use Wilcoxon Signed-Rank test to assess significant differences in the rating of each phantom.

All ten participants completed all part of the study. All participants could recognize all of the standard views. The average Likert scale was 3.2 for the 3D printed and 2.9 for the commercial Phantom with no significant difference. The average time to obtain views was 24.5 and $30 \mathrm{sec}$ for the $3 \mathrm{D}$ printed and the commercial phantoms respectively statistically significantly in favor of the 3D printed phantom. The qualitative user assessment for ease to obtain the views, probe manipulation, image quality and overall experience were in great favor of the 3D printed phantom. 
Our Study suggest that the quality of TEE images obtained on the 3D printed phantom are not significantly different from those obtained on the commercial Phantom. The ease of use and time required to complete a basic TEE exam were in favor of the 3D Printed phantom. 


\section{References}

1. Shanewise JS, Cheung AT, Aronson S, et al. ASE/SCA guidelines for performing a comprehensive intraoperative multiplane transesophageal echocardiography examination: recommendations of the American Society of Echocardiography Council for Intraoperative Echocardiography and the Society of Cardiovascular Anesthesiologists Task Force for Certification in Perioperative Transesophageal Echocardiography. J Am Soc Echocardiogr 1999;12:884-900.

2. Flachskampf FA, Badano L, Daniel WG, et al. Recommendations for transoesophageal echocardiography: update 2010. Eur J Echocardiogr 2010;11:557-76.

3. Hahn RT, Abraham T, Adams MS, et al. Guidelines for performing a comprehensive transesophageal echocardiographic examination: recommendations from the American Society of Echocardiography and the Society of Cardiovascular Anesthesiologists. J Am Soc Echocardiogr 2013;26:921-64.

4. Reeves ST, Finley AC, Skubas NJ, et al. Basic perioperative transesophageal echocardiography examination: a consensus statement of the American Society of Echocardiography and the Society of Cardiovascular Anesthesiologists. J Am Soc Echocardiogr 2013;26:443-56.

5. Arntfield R, Pace J, McLeod S, Granton J, Hegazy A, Lingard L. Focused transesophageal echocardiography for emergency physicians-description and results from simulation training of a structured four-view examination. Crit Ultrasound J 2015;7:27.

6. Bahner DP, Hughes D, Royall NA. I-AIM: a novel model for teaching and performing focused sonography. J Ultrasound Med 2012;31:295-300.

7. Hilberath JN, Oakes DA, Shernan SK, Bulwer BE, D'Ambra MN, Eltzschig HK. Safety of transesophageal echocardiography. J Am Soc Echocardiogr 2010;23:1115-27; quiz $220-1$. 
8. Jerath A, Vegas A, Meineri M, et al. An interactive online 3D model of the heart assists in learning standard transesophageal echocardiography views. Can J Anaesth 2011;58:14-21.

9. Sharma V, Chamos C, Valencia O, Meineri M, Fletcher SN. The impact of internet and simulation-based training on transoesophageal echocardiography learning in anaesthetic trainees: a prospective randomised study. Anaesthesia 2013;68:621-7.

10. Vegas A, Meineri M, Jerath A, Corrin M, Silversides C, Tait G. Impact of online transesophageal echocardiographic simulation on learning to navigate the 20 standard views. $\mathbf{J}$ Cardiothorac Vasc Anesth 2013;27:531-5.

11. Prat G, Charron C, Repesse X, et al. The use of computerized echocardiographic simulation improves the learning curve for transesophageal hemodynamic assessment in critically ill patients. Ann Intensive Care 2016;6:27.

12. Arntfield R, Pace J, Hewak M, Thompson D. Focused Transesophageal

Echocardiography by Emergency Physicians is Feasible and Clinically Influential:

Observational Results from a Novel Ultrasound Program. J Emerg Med 2016;50:286-94.

13. Mahmood F, Mahmood E, Dorfman RG, et al. Augmented Reality and Ultrasound Education: Initial Experience. J Cardiothorac Vasc Anesth 2018;32:1363-7.

14. Qurash MT, Yaacob NY, Azuan N, Khaleel YS, Zakaria R. Special Ultrasound Phantom for Interventional Training: Construction, Advantages, and Application. J Med Ultrasound 2018;26:210-4.

15. Morrow DS, Cupp JA, Broder JS. Versatile, Reusable, and Inexpensive Ultrasound Phantom Procedural Trainers. J Ultrasound Med 2016;35:831-41.

16. Schwartz CM, Ivancic RJ, McDermott SM, Bahner DP. Designing a Low-Cost Thyroid Ultrasound Phantom for Medical Student Education. Ultrasound Med Biol 2020;46:1545-50. 
17. Smith SW, Lopath PD, Adams DB, Walcott GP. Cardiac ultrasound phantom using a porcine heart model. Ultrasound Med Biol 1995;21:693-7.

18. Martensson M, Winter R, Cederlund K, et al. Assessment of left ventricular volumes using simplified 3-D echocardiography and computed tomography - a phantom and clinical study. Cardiovasc Ultrasound 2008;6:26.

19. McLeod AJ, Currie ME, Moore JT, et al. Phantom study of an ultrasound guidance system for transcatheter aortic valve implantation. Comput Med Imaging Graph 2016;50:2430.

20. Petrini J, Eriksson MJ, Caidahl K, Larsson M. Circumferential strain by velocity vector imaging and speckle-tracking echocardiography: validation against sonomicrometry in an aortic phantom. Clin Physiol Funct Imaging 2018;38:269-77.

21. Coles-Black J, Chao I, Chuen J. Three-dimensional printing in medicine. Med J Aust 2017;207:102-3.

22. Maier SK, Hahne H, Gholami AM, et al. Comprehensive identification of proteins from MALDI imaging. Mol Cell Proteomics 2013;12:2901-10.

23. Vukicevic M, Mosadegh B, Min JK, Little SH. Cardiac 3D Printing and its Future Directions. JACC Cardiovasc Imaging 2017;10:171-84.

24. Wang DD, Gheewala N, Shah R, et al. Three-Dimensional Printing for Planning of Structural Heart Interventions. Interv Cardiol Clin 2018;7:415-23.

25. Harb SC, Rodriguez LL, Vukicevic M, Kapadia SR, Little SH. Three-Dimensional Printing Applications in Percutaneous Structural Heart Interventions. Circ Cardiovasc Imaging 2019;12:e009014.

26. Meier LM, Meineri M, Qua Hiansen J, Horlick EM. Structural and congenital heart disease interventions: the role of three-dimensional printing. Neth Heart J 2017;25:65-75. 27. Hermsen JL, Roldan-Alzate A, Anagnostopoulos PV. Three-dimensional printing in congenital heart disease. J Thorac Dis 2020;12:1194-203. 
28. Schmauss D, Haeberle S, Hagl C, Sodian R. Three-dimensional printing in cardiac surgery and interventional cardiology: a single-centre experience. Eur J Cardiothorac Surg $2015 ; 47: 1044-52$.

29. Yamada T, Osako M, Uchimuro T, et al. Three-Dimensional Printing of Life-Like Models for Simulation and Training of Minimally Invasive Cardiac Surgery. Innovations (Phila) 2017;12:459-65.

30. Alonzo M, AnilKumar S, Roman B, Tasnim N, Joddar B. 3D Bioprinting of cardiac tissue and cardiac stem cell therapy. Transl Res 2019;211:64-83.

31. Cui H, Miao S, Esworthy T, et al. 3D bioprinting for cardiovascular regeneration and pharmacology. Adv Drug Deliv Rev 2018;132:252-69.

32. Gjelvold B, Mahmood DJH, Wennerberg A. Accuracy of surgical guides from 2 different desktop 3D printers for computed tomography-guided surgery. J Prosthet Dent 2019;121:498-503.

33. Kamio T, Suzuki M, Asaumi R, Kawai T. DICOM segmentation and STL creation for 3D printing: a process and software package comparison for osseous anatomy. 3D Print Med 2020;6:17.

34. Yushkevich PA, Piven J, Hazlett HC, et al. User-guided 3D active contour segmentation of anatomical structures: significantly improved efficiency and reliability. Neuroimage 2006;31:1116-28. 
6. Appendices

6.1. Darstellung des eigenes Beitrags 
Erklärung des eigenes wissenschaftlichen Beitrags zur Publikationspromotion:

In Rahmen der Vorbereitung dieser Promotionsarbeit wurde von mir folgendes Vorgenommen:

- Gestaltung dieser prospektiven Studie

- Schreiben des Protokolls und Ethikkommission Beantrag

- Literaturübersicht zum Thema "Transesophageale Echokardiographie, Simulation und Lehrer"

- Schreiben des Manuskripts zur Veröffentlichung

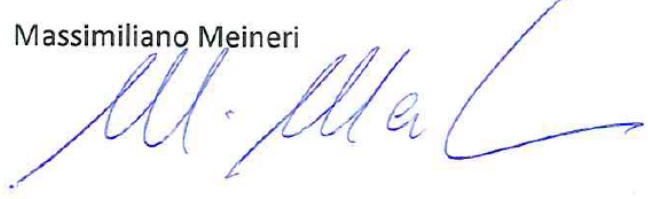

Azad Mashari

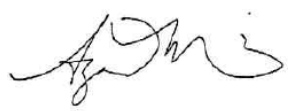

Jacobo Moreno Garijo

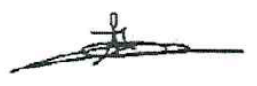

Giulia Maria Ruggeri

Gjuliemarie rugoger

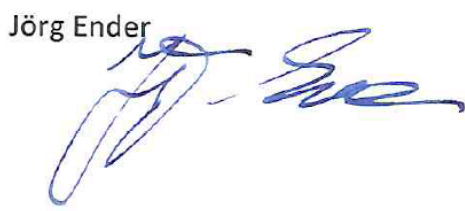




\subsection{Erklärung über die eigenständige Abfassung der Arbeit}

Hiermit erkläre ich, dass ich die vorliegende Arbeit selbstständig und ohne unzulässige Hilfe oder Benutzung anderer als der angegebenen Hilfsmittel angefertigt habe. Ich versichere, dass Dritte von mir weder unmittelbar noch mittelbar eine Vergütung oder geldwerte Leistungen für Arbeiten erhalten haben, die im Zusammenhang mit dem Inhalt der vorgelegten Dissertation stehen, und dass die vorgelegte Arbeit weder im Inland noch im Ausland in gleicher oder ähnlicher Form einer anderen Prüfungsbehörde zum Zweck einer Promotion oder eines anderen Prüfungsverfahrens vorgelegt wurde. Alles aus anderen Quellen und von anderen Personen übernommene Material, das in der Arbeit verwendet wurde oder auf das direkt Bezug genommen wird, wurde als solches kenntlich gemacht. Insbesondere wurden alle Personen genannt, die direkt an der Entstehung der vorliegenden Arbeit beteiligt waren. Die aktuellen gesetzlichen Vorgaben in Bezug auf die Zulassung der klinischen Studien, die Bestimmungen des Tierschutzgesetzes, die Bestimmungen des Gentechnikgesetzes und die allgemeinen Datenschutzbestimmungen wurden eingehalten. Ich versichere, dass ich die Regelungen der Satzung der Universität Leipzig zur Sicherung guter wissenschaftlicher Praxis kenne und eingehalten habe. 
6.3. Lebenslauf

\section{Persönliche Informationen}

Name

Geburtsdatum

Geburtsort

Nationalität

Familienstand

Dienststellung

Dienstanschrift

Privatanschrift
Dr. Massimiliano Meineri

01.03 .1974

Pinerolo, Italien

Italienisch

verheiratet mit Rosa Maria Cabrerizo Sanchez, zwei Kinder

Leitender Oberarzt

Abteilung für Anästhesiologie und Intensivmedizin Herzzentrum Leipzig

Strümpellstraße 39

04289 Leipzig

Forststr. 8

04229 Leipzig

Deutschland

\section{Akademische Qualifikationen}

01.07.2019

01.07.2007

01.08 .2006
Full Professor

Universität Toronto

Abteilung für Anästhesiologie

Abteilung für Intensivmedizin

Associate Professor

Universität Toronto

Abteilung für Anästhesiologie

Abteilung für Intensivmedizin

Assistant Professor

Universität Toronto

Abteilung für Anästhesiologie 


\section{Akademische Ausbildung}

06.1993

Klassisches Abitur, Liceo Ginnasio G.F. Porporato, Pinerolo, Italien. 60/60

1993-1999

Medizinstudium an der Universita' degli Studi Torino, Italien

19.10.1999

Medizin Doktor, Universita' degli Studi Torino, Torino, Italien. Thesis: „Dräger Physioflex und closed loop Anesthäsie, klinische Erfahrung". 110/110 Cum Laude.

10.05 .2000

10.05 .2000

$10.1999-12.2003$

Staat Exam, Universita' degli Studi Torino, Torino, Italien 110/110 punkte.

Approbation als Arzt, Ordine dei Medici della Provincia di Torino, Torino, Italien

Weiterbildungszeit als Assistenzarzt der Klinik für Anästhesiologie und Intensivtherapie am Universitätsklinikum Torino, Italien.

Facharztprüfung und Thesis Vorstellung: "Incore One LVAD: klinische Erfahrung und Literaturbewertung" 70/70 Cum Laude

30.06.2006

Examination of Special Competence, Perioperative Transesophageal Echocardiography, National Board of Echocardiography, USA

Certification, Advanced Perioperative Transesophageal Echocardiography, National Board of Echocardiography, USA

10. $2015-05.2016$

UHN-Rotman Leadership Development Program, Management, Rotman School of Management, Toronto, Ontario, Kanada

30.06 .2016

Re-Certification, Advanced Perioperative Transesophageal Echocardiography, National Board of Echocardiography, USA

24.05.2019

Deutsche Approbation als Arzt der Sächsischen

Landesärztekammer

06.09.2019

Facharztanerkennung der Sächsischen Landesärztekammer 


\section{Berufliche Qualifikationen}

$1999-2003$

12. $2003-06.2004$

01.07.2004-31.08. 2006

01.08.2006-30.06.2019

01.07.2012-30.06.2019

01.10.2014 - 30.06.2019 Gründer und Direktor Advanced Perioperative Imaging Laboratory, Toronto General Hospital, Toronto, ON, Kanada (www.apil.ca)

01.07.2019 - 30.09.2019 Oberarzt der Abteilung für Anästhesiologie und Intensivmedizin Hezzentrum Leipzig, Leipzig

01.10 .2019

Leitender Oberarzt der Abteilung für Anästhesiologie und Intensivmedizin Hezzentrum Leipzig, Leipzig

\section{Auszeichnung}

$2010-2011$

$2010-2011$

$2011-2012$

$2015-2016$

$2016-2017$
Weiterbildungszeit als Assistenzarzt der Klinik für Anästhesiologie und Intensivtherapie am Universitätsklinikum Torino, Italien.

Facharzt der Abteilung für Anästhesiologie, Ospedale San Giovanni Battista, Torino, Italien

Fellowship, Cardiovascular Anesthesiology, Toronto General Hospital, Toronto, Ontario, Kanada
Direktor „Perioperative Echocardiography Group“ Toronto Genrral Hospital, Toronto, ON, Kanada 


\section{Reviewer}

2018-

2018 -

2017 -

2017 -

2015 -

2014 -

2013-

2011-

\section{Mitgliedschaft}

2019-

2019-

$2011-$

2008 -

$2006-2019$

$2006-2019$

$2005-2019$

$2000-2019$

$2002-2004$
European Journal of Cardiothoracic Surgery

BMC Anesthesiology

Saudi Journal of Anesthesia

Critical Ultrasound Journal

Journal of Heart and Lung Transplantation

Canadian Journal of Anesthesia

Anesthesia and Analgesia

Minerva Anestesiologica
Deusche Gesellschaft für Anästhesiologie und Intensivmedizin European Association for Cardiothoracic Anesthesiology

American Society of Echocardiography

Society of Cardiovascular Anesthesiology

Member, Ontario Medical Association

Member, Toronto General Hospital, Medical Staff Association

Member, Canadian Anesthesiologists' Society

Member, College of Physician and Surgeons of the Province of Torino, Torino, Italy

Member, Italian Society of Anesthesia

\section{Sprachkenntnisse}

Italienisch: Muttersprache

Deutsch: B2

Englisch: fließend in Wort und Schrift

Spanisch: fließend in Wort und Schrift

Französisch: gute Kenntnisse 


\subsection{Publikationen und Vorträge}

1. Moreno Garijo J, Amador Y, Fan CS, Woo A, Ralph Edwards A, Silverton N, Mashari A, Meineri M. Association between three dimension left ventricular outflow tract area and gradients post myectomy in hypertrophic obstructive cardiomyopathy. J Cardiothorac Vasc Anesth 2020 ePub ahead of print

2. Meineri M, Qua-Hiansen J, Garijo JM, et al. Evaluation of a Patient-Specific, Low-Cost, 3-Dimensional-Printed Transesophageal Echocardiography Human Heart Phantom. J Cardiothorac Vasc Anesth 2021;35:208-15.

3. Elgamal H, Borger M, Ender J, Meineri M. Intraoperative Diagnosis of Subaortic Stenosis in a Young Patient Scheduled for Elective Aortic Valve Replacement. A A Pract 2020;14:e01288.

4. Ender JK, Seidel R, Brendgen S, Heiden A, Strumpf J, Scroeder A, Meineri M. Entwichlung eines integrierten Blended-Learning-Curriculums zum erlernrn fokusierter Sonographie. Anästh Intensivmed 2020;61:358-64

5. Elgamal H, Luedi MM, Ender JK, Meineri M. Preoperative management of anticoagulation in the surgical patient: Highlights of the latest guidelines. Best Pract Res Clin Anaesthesiol 2020;34:141-52.

6. Gregory AJ, Grant MC, Manning MW, et al. Enhanced Recovery After Cardiac Surgery (ERAS Cardiac) Recommendations: An Important First Step-But There Is Much Work to Be Done. J Cardiothorac Vasc Anesth 2020;34:39-47.

7. Lembrikov I, Mashari A, Hiansen JQ, Oechslin E, Hickey E, Meineri M. Intraoperative Transesophageal Echocardiography in a Rare Case of Dextrocardia, Situs Inversus Totalis, and Double-Outlet Right Ventricle. A A Pract 2020;14:123-6.

8. Meier I, Vogt AP, Meineri M, Kaiser HA, Luedi MM, Braun M. Point-of-care ultrasound in the preoperative setting. Best Pract Res Clin Anaesthesiol 2020;34:315-24.

9. Meineri M, Arellano R, Bryson G, et al. Canadian recommendations for training and performance in basic perioperative point-of-care ultrasound: recommendations from a consensus of Canadian anesthesiology academic centres. Can J Anaesth 2020.

10. Ribeiro RVP, Alvarez JS, Yu F, Adamson M B, Paradiso E, Mbadjeu Hondjeu A R, Xin L, Gellner B, Degen M, Bissoondath V, Meineri M, Rao V, Badiwala M V. Comparing Donor Heart Assessment Strategies During Ex Situ Heart Perfusion to Better Estimate Posttransplant Cardiac Function. Transplantation 2020;104:1890-8.

11. Rong LQ, Palumbo MC, Rahouma M, Meineri M, Arguelles GR, Kim J, Lau C, Devereux RB, Pryor KO, Girardi LN, Redaelli A, Gaudino MFL, Weinsaft JW. Immediate Impact of Prosthetic Graft Replacement of the Ascending Aorta on Circumferential Strain in the Descending Aorta. Eur J Vasc Endovasc Surg. 2019 Oct;58(4):521-528.

12. Bello C, van Rensburg A, Meineri M, Luedi MM. Eye Drops: Must-Knows for Anesthesiology and Perioperative Care. A A Pract. 2019 Aug 15;13(4):155-157. 
13. Ribeiro RVP, Alvarez JS, Yu F, Adamson MB, Fukunaga N, Serrick C, Bissoondath V, Meineri M, Badiwala MV, Rao V. A Pre-Clinical Porcine Model of Orthotopic Heart Transplantation. J Vis Exp. 2019 Apr 27;(146).

14. Ribeiro RVP, Alvarez JS, Yu F, Paradiso E, Adamson MB, Maria Ruggeri G, Fukunaga N, Bissoondath V, Serrick C, Meineri M, Ross H, Rao V, Badiwala MV. Hearts Donated After Circulatory Death and Reconditioned Using Normothermic Regional Perfusion Can Be Successfully Transplanted Following an Extended Period of Static Storage. Circ Heart Fail. 2019 Apr;12(4).

15. Beuth J, Falter F, Pinto Ribeiro R, Badiwala M, Meineri M, New Strategies to expand and optimize heart donor pool: Ex-Vivo Heart Perfusion and Donation after Circulatory Death. Review of current research and future trends. Anesthesia and Analgesia. 2018. 128 (3), 406-413. Senior Responsible Author.

16. Ballocca F, Ruggeri G, Roscoe A, Thampinathan B, David TE, Lang RM, Meineri M, Tsang W. Aortic root Changer before and after surgery for chronic aortic dilatation: a 3D echocardiographic study. Echocardiography, 36 (2): 376-385.

17. Ballocca F, Meier LM, Ladha K, Qua Hiansen J, Horlick EM, Meineri M. Validation of Quantitative 3D TEE Mitral Valve Analysis Using Stereoscopic Display. Journal of cardiothoracic and vascular anesthesia. 2018. 33 (3): 732-741.

18. Ruggeri G, Qua Hiansen J, Pivetta E, Mashari A, Ballocca F, Pinto Ribeiro RV, Xin L, Badiwala M, Thampinathan B, Meineri M. Description of a novel set-up for functional echocardiographic assessment of left ventricular performance during ex vivo heart perfusion. Anesthesia and Analgesia. 2018 Sep;127(3):e36-39.

19. Mashari A, Fisher J, Fedorko L, Wąsowicz M, Meineri M. Technology III: In-line vaporizer with reflector. Journal of Clinical Monitoring and Computing. 2018 Aug;32(4):647-650..

20. Arboleda Salazar R, Heggie J, Wolski P, Horlick E, Osten M, Meineri M. Anesthesia for percutaneous pulmonary valve implantation: a case series. Anesthesia and Analgesia. $2018 \mathrm{Jul} ; 127(1): 39-45 .$.

21. Fayad A, Shillcutt S, Meineri M, Ruddy T, Ansari MT. Comparative effectiveness and harms of intraoperative transesophageal echocardiography in non-cardiac surgery: A systematic review. Seminars in Cardiothoracic and Vascular Anesthesia. 2018 Jun;22(2):122-136.

22. Wąsowicz M, Jerath A, Luksun W, Sharma V, Mitsakakis N, Meineri M, Katznelson R, Yau T, Rao V, Beattie WS Comparison of propofol-based versus volatile-based anaesthesia and postoperative sedation in cardiac surgical patients: a prospective, randomized, study. Anaesthesiology Intensive Therapy. 2018 ;50(3):200-209.

23. Mashari A, Montealegre-Gallegos M. Jeganathan J, Yeh L, Qua Hiansen J, Meineri M, Mahmood F, Matyal R. Low-cost 3D printed phantom for neuraxial anesthesia training: Development and comparison to a commercial model. PLoS One. 2018;13(6):e0191664.

24. Haque M, Van Rensburg A, McCluskey S, Meineri M, Parotto M. In Situ Cold Perfusion of the Liver on Cardiopulmonary Bypass: Coagulopathy and Its Correction: A Case Report. A A Pract. 2018 Nov 15;11(10):263-267. 
25. Luzzi C, Rao V, Meineri M. Intraoperative 3D TEE assessment of valvular geometry after implantation of Basal Annuloplasty of Cardia Externally (BACE) device for ischemic mitral regurgitation. A A Pract. 2018 Oct 1;11(7):201-203.

26. Meineri M, Bryson G, Arellano R, Skubas N. Core curriculum in point of care ultrasound: What does the anesthesiologist need to know? Canadian Journal of Anesthesia. 2018 Apr;65(4):417-426.

27. Mashari A, Fedorko L, Fisher J, Klein M, Wąsowicz M, Meineri M. High volatile anaesthetic conservation with a digital in-line vaporizer and a reflector. Acta Anaesthesiologica Scandinavica. 2018 Feb;62(2):177-185.

28. Liming Xin L, Gellner B, Pinto Ribeiro RV, Ruggeri GM, Banner D, Meineri M, Rao V, $\mathrm{Zu} \mathrm{Z}$, Badiwala M. A new multi-mode perfusion system for ex vivo heart perfusion study. Journal of Medical Systems. 2018; 42:25.

29. Demarchi L Meineri M. POCUS in perioperative medicine: a North American perspective. Critical Ultrasound Journal. 2017 Oct ;9(1):19. Senior Responsible Author.

30. Parotto M, Jiansen JQ, AboTaiban A, Ioukhova S, Agzamov A, Cooper R, O'Leary G, Meineri M. Evaluation of a low cost, 3D-printed model for bronchoscopy training. Anaesthesiology Intensive Therapy. 2017;49(3):189-197.

31. Moreno Garijo J, Mashari M, Meineri M. Role of transesophageal echocardiography in general anesthesia. Current Anesthesiology Reports. 2017 Sep;7(3):273-282.

32. Yeoh T, Venkatraghavan L, Fisher J, Meineri M. Is there blood flow in the internal jugular vein in the upright position? An Ultrasound study on healthy volunteers. Canadian Journal of Anesthesia. 2017 Aug;64(8):854-859.

33. Moreno Garijo J, Wijeysundera DN, Munro JC, Meineri M. Correlation between transhepatic and subcostal inferior vena cava views to assess inferior vena cava variation: A pilot study. Journal of Cardiothoracic and Vascular Anesthesia. 2017 Jun;31(3):973979.

34. Silverton N, Meineri M. Speckle Tracking Strain of the Right Ventricle: An Emerging Tool for Intraoperative Echocardiography. Anesthesia and Analgesia. 2017 Nov;125(5):1475-1478. Senior Responsible Author.

35. Corredor C, Horlick E, Tsang W, Meineri M. Double trouble: A case of periprocedural detection of intracardiac thrombus and aortic root dissection during emergent transfemoral TAVR. Echocardiography. 2017 Mar;34(3):462-464.

36. Meier LM, Meineri M, Hiansen JQ, Horlick EM. Review article: Structural and congenital heart disease interventions: The role of three-dimensional Printing. Netherlands Heart Journal. 2017 Feb;25(2):65-75.

37. Alcaraz G, Meineri M, Dattilo K, Wąsowicz M. Intraoperative transesophageal echocardiographic diagnosis of acute budd-chiari syndrome after extended right hepatectomy. Anesthesia and Analgesia Case Reports. A Case Rep. 2016 Jul;7(1):13-15.

38. Meineri M. Imaging in thoracic surgery. Current Anesthesiology Reports. 2016 Jun;6(2):150-159. 
39. Meineri M. Transesophageal echocardiography - what the anesthesiologist has to know. Minerva Anestesiologica. 2016 Aug;82(8):895-907.

40. Parotto M, Jariani M, Wijeysundera D, Meineri M. Early thrombus formation of a pulmonary artery catheter. Intensive Care Medicine. 2015 Oct;41(10):1831-1832. Senior Responsible Author.

41. Calleja A, Poulin F, Woo A, Meineri M, Jedrzkiewicz S, Vannan MA, Rakowski H, David T, Tsang W, Thavendiranathan P. Quantitative modeling of the mitral valve by 3D transesophageal echocardiography in patients undergoing mitral valve repair: correlation with intraoperative surgical technique. Journal of the American Society of Echocardiography. 2015 Sep;28(9):1083-1092.

42. Ogilvie E, Vlanchou A, Edsell E, Fletcher SN, Valencia O, Meineri M, Sharma V. Simulation-based teaching is more effective than point-of-care teaching to assist trainees to identify basic transesophageal echocardiography views: A prospective randomized study. Anaesthesia. 2015 Mar;70(3):330-335.

43. Ashes K, M Yu, Meineri M, Katznelson R, Carroll J, Rao V, Djaiani G. Diastolic dysfunction, cardiopulmonary bypass and atrial fibrillation after coronary artery bypass graft surgery. British Journal of Anesthesia. 2014 Nov;113(5):815-821.

44. Tourmousoglou C, Meineri M, Feindel C, Brister S. Repair of aorto-left ventricular fistulas following prosthetic valve endocarditis. Journal of Cardiac Surgery. $2013 \mathrm{Nov}$ 28;28(6):654-659. Co-Principal Author.

45. Tsang W, Meineri M, Hahn RT, Veronesi F, Shah AP, Osten M, Nathan S, Russo M, Lang RM and Horlick EM. A three-dimensional echocardiographic study on aortic-mitral coupling in transcatheter aortic valve replacement. European Heart J Cardiovasc Imaging. European Heart Journal - Cardiovascular Imaging. 2013 Oct;14(10):950-956.

46. Sharma V, Chamos C, Valencia O, Meineri M, Fletcher SN. The impact of internet and simulation-based training on transoesophageal echocardiography learning in anaesthetic trainees: a prospective randomised study. Anaesthesia. 2013 Jun;68(6):621-627.

47. Vegas A, Meineri M, Jerath A, Corrin M, Silversides C, Tait G. Impact of online transesophageal echocardiographic simulation on learning to navigate the 20 standard views. Journal of Cardiothoracic and Vascular Anesthesia. 2013 Jun;27(3):531-535. CoPrincipal Author.

48. Mardimae A, Balaban DY, Machina MA, Han JS, Katznelson R, Minkovich LL, Fedorko L, Murphy PM, Wasowicz M, Naughton F, Meineri M, Fisher JA, Duffin J. The interaction of carbon dioxide and hypoxia in the control of cerebral blood flow. Pflügers Archiv. 2012 Oct;464(4):345-351.

49. Biaggi P, Jedrzkiewicz S, Gruner C, Meineri M, Karski J, Vegas A, Tanner FT, David TE, Rakowski H, Woo A. Three-Dimensional Transesophageal Echocardiography in Patients with Advanced Mitral Valve Prolapse: Quantification of Mitral Valve Anatomy correlates with the Complexity of Mitral Valve Repair. Journal of the American Society of Echocardiography. 2012 Jul;25(7):758-65. 
50. Meineri M, Van Rensburg AE, Vegas A. Right ventricular failure after LVAD implantation prevention and treatment. Best Practice and Research Clinical Anesthesiology. 2012 Jun;26(2):217-229.

51. Sharma V, Anthony G, Hoechlin E, Slinger P, Meineri M. Left anterior descending coronary artery pseudoaneurysm compressing the main pulmonary artery in a patient with behcet's disease. Echocardiography. 2012 Apr;29(4):E91-93.

52. Sharma V, Wasowicz M, Brister S, Karski J, Meineri M. Postoperative transesophageal echocardiography diagnosis of inferior vena cava obstruction after mitral valve repair. Anesthesia and Analgesia. 2011 Dec;113(6):1343-1346.

53. Wasowicz M, Meineri M, Djaiani G, Mitsakakis N, Hegazy N, Xu W, Katznelson R, Karski J. Early complications and immediate postoperative outcomes of paravalvular leaks after valve replacement surgery. Journal of Cardiothoracic and Vascular Anesthesia. 2011 Aug;25(4):610-614.

54. Sharma V, Cusimano RJ, McNama P, Wasowicz M, Ko R, Meineri M. Intraoperative migration of inferior vena cava tumor detected by transesophageal echocardiography. Canadian Journal of Anesthesia. 2011 May; 58(5):468-470.

55. Jerath A, Vegas A, Meineri M, Silversides C, Feindel C, Beattie S, Corrin M, Tait G. An interactive online 3D model of the heart assists in learning standard transesophageal echocardiography views. Canadian Journal of Anesthesia. 2011 Jan;58(1):14-21.

56. Biaggi P, Gruner C, Jedrzkiewicz S, Karski, J, Meineri M, Vegas A, David TE, Woo A, Rakowski H. Assessment of mitral valve prolapse by 3D TEE angled views are keys. Journal of the American College of Cardiology, Cardio Vascular Imaging. 2011 Jan; 4(1):94-97.

57. Wasowicz M, Wijeysundera D, McCluskey S, Meineri M, Karkouti K. Incremented value of TEG to prediction of excessive blood loss after cardiac surgery. Anesthesia and Analgesia. 2010 Aug;111(2):331-338.

58. Vegas A, Meineri M. Three-dimensional transesophageal echocardiography is a major advance for intraoperative clinical management of patients undergoing cardiac surgery: A Core Review. Anesthesia and Analgesia. 2010 Jun; 110(6):1548-1573.

59. Osten MD, Feindel C, Greutmann M, Chamberlain K, Meineri M, Rubin B, Mezody M, Ivanov J, Butany J, Horlick E. Transcatheter aortic valve implantation for high risk patients with severe aortic stenosis using the Edwards Sapien balloon-expandable bioprosthesis: a single centre study with immediate and medium term outcomes. Catheterization and Cardiovascular Interventions. 2010 Mar; 75(4):475-485.

60. Wąsowicz M, Meineri M, Katznelson R, Karski JM. Anaesthesia for adult patient with congenital heart disease - the principles of the perioperative care during noncardiac surgery Part II. Selected aspects of clinical management. Anaesthesiology and Rescue Medicine. 2010; 4:459-468.

61. Wasowicz M, Meineri M, Katznelson R, Heggie J, Vegas A, Karski J. Anaesthesia for adult patient with congenital heart disease - the principles of the perioperative care during noncardiac surgery Part I. Anatomy and pathophysiology. Anaesthesiology and Rescue Medicine. 2010; 4:344-350. 
62. Wąsowicz M, Meineri M, McCluskey SA, Mitsakakis S, Karkouti K. The utility of thrombelastography for guiding recombinant activated factor VII therapy for refractory hemorrhage after cardiac surgery. Journal of Thoracic and Cardiovascular Anesthesia. 2009 Dec; 23(6):828-834.

63. Wasowicz M, Meineri M, Vegas A. Heparin induced thrombocytopenia principles of diagnosis and treatment. Anaesthesiology and Rescue Medicine. 2009; 3:344-350.

64. Ito S, Mardimae A, Han J, Duffin J, Wells G, Fedorko L, Minkovich L, Katznelson R, Meineri M, Arenovich T, Kessler C, Fisher JA. Non-invasive prospective targeting of arterial P(CO2) in subjects at rest. Journal of Physiology. 2008 Aug; 586(15):3675-3682.

65. Wasowicz M, Srinivas C, Meineri M, Banks, B, McCluskey SA, Karkouti K. Technical report: analysis of citrated blood with thromboelastography: comparison with fresh blood samples. Canadian Journal of Anesthesia. 2008 May; 55(5):284-289.

66. Wasowicz M, Meineri M, McCluskey S, Van Rensburg A, Srinivas C, Karkouti K. Analysis of citrated blood with thromboelastography; comparison with fresh samples. Which one is right? European Journal of Anaesthesia. 2007; 24:28.

67. Karkouti K, Yau TM, Riazi S, Dattilo KM, Wasowicz M, Meineri M, McCluskey SA, Wijeysundera DN, van Rensburg A, Beattie WS. Determinants of complications with recombinant factor VIIa therapy for refractory blood loss after cardiac surgery. Canadian Journal of Anesthesia. 2006 Aug;53(8):802-809.

68. Karkouti K, Wijeysundera DN, Yau TM, Callum JL, Meineri M, Wasowicz M, McCluskey SA, Beattie WS. Platelet transfusions are not associated with increased morbidity and mortality in cardiac surgery. Canadian Journal of Anesthesia. 2006 Mar; 53(3):279-287. 


\section{Internationale Veranstaltungen}

30.12.2019 Speaker. Airway Ultrasound, AICT Annual Meeting, Lugano, Switzerland

02.12.2019 Speaker. Mitraclip Workshop. Toronto TEE Symposium, Toronto, Canada

02.12.2019 Speaker. Assessment of Valve prostheses. Toronto TEE Symposium, Toronto, Canada

01.12.2019 Speaker. 3D Anatomy. 3D TEE Course, Toronto, Canada

01.12.2019 Speaker.3D Acquisition. 3D TEE Course, Toronto, Canada

04.12.2019 Speaker. Anticoagulation. EACTS Meeting Lisbon, Portugal

23.06.2019 Speaker. 3D QLab Workshop. EACTA Advanced Echo Course, Gdansk, Poland

23.06.2019 Speaker. Volume Responsiveness. EACTA Advanced Echo Course, Gdansk, Poland

22.06.2019 Speaker. Volume Responsiveness. EACTA Basic Echo Course, Gdansk, Poland

18.06.2019 Speaker. Perioperative POCUS Workshop. Annual Meeting Society of Cardiovascular Anesthesiologists, Chicago, IL, United States.

17.05.2019 Speaker. Lung US Workshop. 2020 Thoracic Anesthesia Meeting Society of Cardiovascular Anesthesiologists, Chicago, IL, United States.

22.02.2019 Speaker. 3D imaging in the perioperative setting. 2019 Annual Meeting The Academy of Anesthesiology, Casa Monica Resort \& Spa, St. Augustine, Florida, United States.

20.02.2019 Speaker. 3D Hands-on acquisition workshop. 22 ${ }^{\text {nd }}$ Society of Cardiovascular Anesthesia, Echo Week, Atlanta Georgia, United States.

19.02.2019 Speaker. Functional Tricuspid regurgitation in left sided disease. $22^{\text {nd }}$ Society of Cardiovascular Anesthesia, Echo Week, Atlanta Georgia, United States.

22.02.2019 Speaker.3D imaging in the perioperative setting. 2020 Annual Meeting The Academy of Anesthesiology, .Casa Monica Resort \& Spa, St. Augustine, Florida, United States.

20.02.2019 Speaker. 3D Hands-on acquisition workshop. $22^{\text {nd }}$ Society of Cardiovascular Anesthesia, Echo Week, Atlanta Georgia, United States.

19.02.2019 . Speaker. Functional Tricuspid regurgitation in left sided disease. $22^{\text {nd }}$ Society of Cardiovascular Anesthesia, Echo Week, Atlanta Georgia, United States.

30.08.2018 Visiting Professor. 3D printing in the perioperative setting. Cardiovascular anesthesia rounds. Department of Anesthesia, Leipzig Herzzentrum, Leipzig, Germany.

25.06.2018 . Speaker. Preload and volume responsiveness assessment. European Association of Cardio Thoracic Anesthesia-Echo Annual Meeting, Athens, Greece 
24.06.2018 Speaker. Concomitant tricuspid valve repair/replacement during LVAD implantation. Contribution of echo in the decision making. European Association of Cardio Thoracic Anesthesia-Echo Annual Meeting, Athens, Greece

24.06.2018 . Speaker. Hemodynamic calculations workshop. European Association of Cardio Thoracic Anesthesia-Echo Annual Meeting, Athens, Greece

23.06.2018 Speaker. Introduction to Hemodynamic calculations. European Association of Cardio Thoracic Anesthesia-Echo Annual Meeting, Athens, Greece

23.06.2018 . Speaker. Transcatheter Procedures: Role of Echocardiography: Do we need Echocardiography in TAVI procedures: Pro. European Association of Cardio Thoracic Anesthesia-Echo Annual Meeting, Athens, Greece.

30.04.2018 . Speaker. Perioperative Ultrasound, Ultrasound in cardiac arrest. Society of Cardiovascular Anesthesiologists, $40^{\text {th }}$ Annual Meeting and workshops, Phoenix, Arizona, United States.

28.04.2018 Speaker. Structured networking circles speed-mentoring breakfast. Society of Cardiovascular Anesthesiologists, $40^{\text {th }}$ Annual Meeting and workshops, Phoenix, Arizona, United States.

28.04.2018 Speaker. Workshop: hands-on TTE. Society of Cardiovascular Anesthesiologists, $40^{\text {th }}$ Annual Meeting and workshops, Phoenix, Arizona, United States.

27.04.2018 Speaker. Workshop: Thoracic ultrasound diagnosis and management. Society of Cardiovascular Anesthesiologists, $7^{\text {th }}$ Thoracic Anesthesia Symposium, Phoenix, Arizona, United States.

27.02.2018 Speaker. Tricuspid regurgitation in left heart disease. $21^{\text {st }}$ Society of Cardiovascular Anesthesia, Echo Week, Atlanta Georgia, United States.

26.02.2018 . Speaker. PBLD: How to treat the moderates: Moderate mitral regurgitation. $21^{\text {st }}$ Society of Cardiovascular Anesthesia, Echo Week, Atlanta Georgia, United States.

26.02.2018 Speaker. Principles of hemodynamic calculations. $21^{\text {st }}$ Society of Cardiovascular Anesthesia, Echo Week, Atlanta Georgia, United States.

03.02.2018 Speaker. Diagnostic and therapeutic impact of TEE in cardiac surgery. $38^{\text {th }}$ Myron B. Laver International Postgraduate Course. Annual Conference of the Department of Anesthesia at University of Basel. Basel, Switzerland.

02.02.2018 Speaker. What ultrasound can what cannot and in five years? $38^{\text {th }}$ Myron B. Laver InternationalPostgraduate Course. Annual Conference of the Department of Anesthesia at University of Basel. Basel, Switzerland.

01.02.2018 . Visiting Professor. 3D printing in perioperative medicine. Departmental grand rounds. Department of Anesthesia, University of Bern, Inselspital, Bern, Switzerland. 
31.01.2018 Visiting Professor. TEE assessment of RV strain. Cardiovascular anesthesia rounds. Department of Anesthesia, University of Bern, Inselspital, Bern, Switzerland.

21.11.2017 Speaker. Wetlab 2017: Aortic valve implantation course: A systematic approach to intraoperative echocardiographic aortic valve assessment. University of Basel, Universitatspital Basel, Basel, Switzerland.

21.11.2017 Visiting Professor. TEE assessment of RV strain. Cardiovascular anesthesia rounds. Department of Anesthesia, University of Basel, Universitatspital Basel, Basel Switzerland.

02.10.2017 . Speaker. AV: A systematic approach. European Association of Cardio Thoracic Anesthesia: Certification TEE Course. Valencia, Spain.

2017 Sept 30 Speaker. RV Strain in the operating room: ready for prime time? European Association of Cardio Thoracic Anesthesia: Advanced TEE Course. Valencia, Spain.

30.09.2017 . Speaker. 3D Workshop. European Association of Cardio Thoracic Anesthesia: Advanced TEE Course. Valencia, Spain.

23.05.2017 Speaker. PBLD: Moderate tricuspid regurgitation. Society for Cardio Vascular Anesthesia: Echo week. Atlanta, Georgia, United States.

22.05.2017 Speaker. Right side and pulmonary circulation. Society for Cardio Vascular Anesthesia: Echo week. Atlanta, Georgia, United States. Presenter(s): Meineri M, Joshi R.

21.05.2017 Speaker. Tricuspid and pulmonic valve: Imaging approach and assessment of pathology. Society for Cardio Vascular Anesthesia: echo week. Atlanta, Georgia, United States.

22.05.2017 Speaker. PBLD: Moderate tricuspid regurgitation: fix it or leave it alone. Society for Cardio Vascular Anesthesia, Annual Meeting. Orlando, Florida, United States.

22.05.2017 Speaker. Point of care ultrasound workshop. Society for Cardio Vascular Anesthesia, Annual Meeting. Orlando, Florida, United States.

22.04.2017 Speaker. Tranthoracic cardiac ultrasound workshop. Society for Cardio Vascular Anesthesia, Annual Meeting. Orlando, Florida, United States.

21.04.2017 Chair. Lung ultrasound workshop. Society for Cardio Vascular Anesthesia, Thoracic Anesthesia Meeting. San Orlando, Florida United States. Presenter(s): Meineri M, Steel A, Ross A.

10.03.2017 Speaker. TEE for mechanical assist devices. Italian Association of Cardio Thoracic Anesthesiologists, Bologna, Italy.

27.05.2016 Speaker. Point-of-care ultrasound in anesthesiology: beyond the lines. SMART Meeting Anesthesia Resuscitation Intensive Care. Milan, Milano, Italy. 
27.05.2016 Chair. Hocus pocus: From the initial magic to a diffuse point-of-care ultrasound (POCUS) practice in anesthesia and intensive care. SMART Meeting Anesthesia Resuscitation Intensive Care. Milan, Milano, Italy.

25.05.2016 Facilitator. Hands-on session. SMART lung ultrasound fundamentals, signs and patterns. Milan, Milano, Italy.

25.05.2016 Speaker. Ultrasound-aided airway management: tracheal intubation, lung separation, evaluation of prandial state, NGT placement. SMART lung ultrasound fundamentals, signs and patterns. Milan, Milano, Italy.

24.05.2016 Presenter. Basic cardiac ultrasound knobology. SMART Winces focused cardiac Ultrasound (WBe). Milan, Italy.

23.05.2016 Facilitator. Tranthoracic echo case interpretation and TTE Simulator. SMART Winces focused cardiac Ultrasound (WBe). Milan, Italy.

23.05.2016 Speaker. FoCUS signs of severe hypovolemia. SMART Winces focused cardiac Ultrasound (WBe). Milan, Italy.

03.05.2016 Speaker. Right Side and Pulmonary Circulation. Society for Cardio Vascular Anesthesia: echo week. Atlanta, Georgia, United States. Presenter(s): Meineri M, Shillcutt S.

02.05.2016 Speaker. Tricuspid and pulmonic valve: Imaging approach and assessment of pathology. Society for Cardio Vascular Anesthesia: Echo Week. Atlanta, Georgia, United States.

01.05.2016 Speaker. Image optimization. Society for Cardio Vascular Anesthesia: Echo Week. Atlanta, Georgia, United States.

23.04.2016 Speaker. Workshop: Lung US. Clinica Davila: Ecografia para especialistas en anestesiólogos medicina de urgencia, cuidados intensivos y perioperatorio. Santiago, Región Metropolitana de Santiago, Chile.

22.04.2016 Speaker. Evaluation of pericardium and tamponade. Clinica Davila: Ecografia para especialistas en anestesiólogos medicina de urgencia, cuidados intensivos y perioperatorio. Santiago, Región Metropolitana de Santiago, Chile.

22.04.2016 Speaker. Workshop: Lung US. Clinica Davila: Ecografia para especialistas en anestesiólogos medicina de urgencia, cuidados intensivos y perioperatorio.

Santiago, Región Metropolitana de Santiago, Chile.

21.04.2016 Speaker. Lung ultrasound and lung pathology. Clinica Davila: Ecografia para especialistas en anestesiólogos medicina de urgencia, cuidados intensivos y perioperatorio. Santiago, Región Metropolitana de Santiago, Chile.

21.04.2016 Speaker. Pleural ultrasound and pleural pathology. Clinica Davila: Ecografia para especialistas en anestesiólogos medicina de urgencia, cuidados intensivos y perioperatorio. Santiago, Región Metropolitana de Santiago, Chile.

02.04.2016 Speaker. Point of care ultrasound workshop. Society for Cardio Vascular Anesthesia, Annual Meeting. San Diego, California, United States. 
01.04.2016 Chair. Lung ultrasound workshop. Society for Cardio Vascular Anesthesia, Thoracic Anesthesia Meeting. San Diego, California, United States.

Presenter(s): Meineri M, Steel A, Ross A.

28.10.2015 Course Director. Winfocus basic echocardiography course. Networking World Anesthesia Conference, Cleveland Clinic Abu Dhabi. Abu Dhabi, United Arab Emirates. First UAE Winfocus Echocardiography Course.

23.03.2015 Chair. First Hands-on Preoperative Echocardiography Course. Azienda Ospedaliera Sant Maria Nuova Reggio Emilia. Reggio Emilia, Reggio Emilia, Italy.

02.05.2015 Facilitator. Echocardiography workshop. Networking World Anesthesia Conference. Vancouver, British Columbia, Canada.

01.05.2015 Speaker. Is there any way to prevent excessive bleeding? Networking World Anesthesia Conference. Vancouver, British Columbia, Canada.

201.05.2015 Speaker. Local anesthesia and sedation is the way to go for TAVI.

Networking World Anesthesia Conference. Vancouver, British Columbia, Canada.

10.04.2015 Speaker. Lung ultrasound workshop. Society for Cardio Vascular Anesthesia, Thoracic Anesthesia Meeting. Washington, District of Columbia, United States.

28.03.2015 Speaker. Extended application of ultrasound in anesthesia. Western Anaesthesia Society. Galway, Galway, Ireland.

27.03.2015 Speaker. Basic echocardiography workshop. Western Anaesthesia Society. Galway, Galway, Ireland.

25.03.2015 Visiting Professor. TEE for ECMO. Universita' di Milano Bicocca, Ospedale san Gerardo di Monza. Monza, Monza e Brianza, Italy.

07.09.2014 Speaker. TEE for HOCM. Indian Association of Cardiothoracic Anesthetists. Bangalore, Karnataka, India.

07.09.2014 Facilitator. Heart dissection workshop. Indian Association of Cardiothoracic Anesthetists. Bangalore, Karnataka, India.

01.05.2014 Facilitator. Lung isolation workshop. Networking. World Anesthesia Conference. Vienna, Austria.

30.04.2014 Speaker. The role of TEE in thoracic surgery. Networking World Anesthesia Conference. Vienna, Wien, Austria.

29.04.2014 Chair. Point of care ultrasound course. Department of Anesthesia University of Padova. Padova, Italy.

28.04.2014 Speaker. Introduction to TEE. Department of Anesthesia. University of Padova. Padova, Italy.

29.03.2014 Speaker. Lung ultrasound workshop. Society for Cardio Vascular Anesthesia, Thoracic Anesthesia Meeting. New Orleans, Louisiana, United States. 
14.09.2013 Visiting Professor. Point of care ultrasound in the perioperative setting. Hospital-wide rounds. Kuwait Cancer Care Centre. Kuwait City, Kuwait.

04.09.2013 Speaker. TEE simulation workshop. Indian Association of Cardiothoracic Anesthetists. Bangalore, Karnataka, India.

03.09.2013 Speaker. TEE for transcatheter Aortic valve Implantation. Indian Association of Cardiothoracic Anesthetists. Bangalore, Karnataka, India.

06.04.2013 Speaker. Lung ultrasound workshop. Society for Cardio Vascular Anesthesia, Thoracic Anesthesia Meeting. Miami, Florida, United States.

09.03.2013 Speaker. The role of the anesthesiologist in imaging for TAVI. American College of Cardiology Annual Meeting. San Francisco, California, United States.

05.03.2013 Speaker. Growing pains and beyond: lessons learnt from TAVI's. South African Society of Anesthesia, Annual Meeting. Port Elizabeth, South Africa.

04.03.2013 Speaker. An introduction to point-of-care ultrasound. South African Society of Anesthesia, Annual Meeting. Port Elizabeth, South Africa.

24.02.2013 Visiting Professor. Point of care ultrasound, practical demonstration and didactic talks. FOCUS TTE, Lung, Abdominal, Vascular Ultrasound. University of Stellenbosch, Tygerberg Hospital. Cape Town, South Africa.

22.04.2012 Speaker. Lung ultrasound workshop. Society for Cardio Vascular Anesthesia, Thoracic Anesthesia Meeting. Boston, Massachusetts, United States.

22.04.2012 Speaker. BPLD: Thoracothomy in the opioid tolerant patient. Society for Cardio Vascular Anesthesia, Thoracic Anesthesia Meeting. Boston, Massachusetts, United States.

18.09.2011 Visiting Professor. Thoracic epidurals. Kuwait Cancer Care center. Department of Anesthesia, Round. Kuwait City, Kuwait.

18.09.2011 Visiting Professor. FOCUS TTE hands-on course. Kuwait Cancer Care center. Department of Anesthesia. Kuwait City, Kuwait.

16.09.2011 Speaker. TEE for endovascular procedures: assessment of results. Intraoperative transesophageal echocardiography advanced course. Italian Society of Anesthesia, Analgesia and Intensive Care, Cardiovascular and Thoracic Anesthesia Session. Bergamo, Italy.

16.09.2011 Speaker. Real time 3D TEE: Introduction to the technology. Intraoperative Transesophageal Echocardiography Advanced Course, Italian Society of Anesthesia, Analgesia and Intensive Care, Cardiovascular and Thoracic Anesthesia Session. Bergamo, Italy.

16.09.2011 Speaker. Real time 3D TEE: Mitral valve and left ventricle. Intraoperative Transesophageal Echocardiography Advanced Course. Italian Society of Anesthesia, Analgesia and Intensive Care, Cardiovascular and Thoracic Anesthesia Session. Bergamo, Italy.

16.09.2011 Speaker. Real time 3D TEE: Aortic valve. Intraoperative Transesophageal Echocardiography Advanced Course. Italian Society of Anesthesia, Analgesia 
and Intensive Care, Cardiovascular and Thoracic Anesthesia Session. Bergamo, Italy.

11.09.2011 Visiting Professor. Ultrasound guided central venous access. Kuwait Cancer Care center. Department of Anesthesia, Round. Kuwait City, Kuwait.

11.09.2011 Visiting Professor. FOCUS TTE hands-on course. Kuwait Cancer Care center. Department of Anesthesia. Kuwait City, Kuwait.

17.05.2011 Visiting Professor. FOCUS TTE in the ICU. Kuwait Cancer Care Center. Department of Anesthesia, hands-on workshop. Kuwait City, Kuwait.

16.05.2011 Visiting Professor. FOCUS TTE in the perioperative setting. Kuwait Cancer Care center. Department of Anesthesia, Grand Round. Kuwait City, Kuwait.

15.05.2011 Visiting Professor. Ultrasound guided vascular access. Kuwait Cancer Care center. Department of Anesthesia, Round. Kuwait City, Kuwait.

10.05.2011 Visiting Professor. FOCUS transthoracic echocardiography in the perioperative setting. FOCUS TTE workshop. Department of Anesthesia, Universita' di Padova, Departmental Rounds. Azienda Ospedaliera di Padova, Padova, Italy.

11.10.2010 Visiting Professor. Integrate 3D TEE into your practice. Residents lunch and learn. Anesthesia for percutaneous cardiac interventions. Department of Anesthesia, Washington University, Combined Grand Rounds. Saint Louis, Missouri, United States.

19.08.2010 Visiting Professor. Clinical application of 3D TEE. Department of Anesthesia, Zhengzhou University, Grand Rounds. Zhengzhou, China.

16.08.2010 Visiting Professor. Anesthesia for transcatheter aortic valve implantation. Department of Anesthesia, Chengdu University, Departmental Rounds. Chengdu, China.

12.08.2010 Visiting Professor. Imaging in Anesthesia. Clinical application of 3D TEE. Chinese Society of Anesthesia National Meeting. Chengdu, China.

09.08.2010 Visiting Professor. Introduction to 3D TEE. Department of Anesthesia, First Peking University Hospital, Departmental Rounds. Beijing, China.

26.05.2010 Visiting Professor. 3D TEE a significant advance in intraoperative clinical management. Department of Anesthesia, Universita' di Padova, Departmental Rounds. Azienda ospedaliera di Padova, Padova, Italy.

25.05.2010 Visiting Professor. Lung Transplant Program at Toronto General Hospital. Universita' di Brescia, Grand Rounds. Ospedali riuniti di Bergamo, Bergamo, Italy.

24.05.2010 Visiting Professor. TEE for Lung transplant Surgery. Universita' degli Studi di Milano, Transplant Rounds. Policlinico di Milano, Milano, Italy.

10.06.2009 Visiting Professor. T-C AVI, TGH experience. Grand Rounds, Department of Anesthesia University of Granada. Granada, Spain.

15.04.2008 Visiting Professor. Perioperative management of T-C AV implantation. Santa Croce Hospital, Division of Cardiovascular Surgery. Cuneo, Italy. 
07.04.2008 Visiting Professor. Perioperative management of T-C AV implantation. Mauriziano Umberto I Hospital, Division of Cardiovascular Surgery. Torino, Italy.

20.12.2007 Visiting Professor. Future of AVR: T-C AVR, TGH experience. Niguarda Ca' Granda Hospital Division of Cardiovascular Surgery. Milano, Italy.

11.06.2007 Visiting Professor. Update on Fast track cardiac Anesthesia. Department of Anesthesia University of Torino Residents Rounds. Torino, Italy.

27.09.2006 Visiting Professor. TEE practical intraoperative demonstration and didactic talks. TEE, Basic Views, TEE Advanced Cases. University of Stellenbosch, Tygerberg Hospital. Cape Town, South Africa.

Kanada

01.11.2018 Speaker. Perioperative POCUS. Canadian Critical Care Forum.. Toronto, Ontario, Canada.

11.08.2018 Course Director. Third Canadian Winfocus Echocardiography Course. Winfocus: Basic Echocardiography Course. Department of Anesthesia \& Interdivision of Critical Care, University of Toronto, Toronto, Ontario, Canada.

15.06.2018 Course Director. Third Canadian perioperative point-of-care ultrasound course. Canadian Anesthesiologists' Society Meeting. Montreal, Quebec, Canada.

25.06.2017 Speaker. Point of care ultrasound. Acute Critical Event Simulation. Critical Care fellows Point of Care Ultrasound Course. Royal College of Physician and Surgeons' of Canada, Toronto, Ontario, Canada.

25.06.2017 Speaker. Point of care ultrasound. Canadian Anesthesiologists' Society Meeting. Niagara Falls, Ontario, Canada.

23.06.2017 Course Director. Second Canadian perioperative point-of-care ultrasound course. Canadian Anesthesiologists' Society Meeting. Niagara Falls, Ontario, Canada.

07.05.2017 Speaker. RV function. Third Canadian Winfocus Echocardiography Course. Winfocus: Basic Echocardiography Course. Department of Anesthesia \& Interdivision of Critical Care, University of Toronto, Toronto, Ontario, Canada.

06.05.2017 Course Director. Third Canadian Winfocus Echocardiography Course. Winfocus: Basic Echocardiography Course. Department of Anesthesia \& Interdivision of Critical Care, University of Toronto, Toronto, Ontario, Canada.

06.05.2017 Course Co-Director. Third Canadian Winfocus: Basic Echocardiography Course. Department of Anesthesia \& Interdivision of Critical Care, University of Toronto, Toronto, Ontario, Canada. 
06.05.2017 Speaker. Lung US. Third Canadian Winfocus: Basic Echocardiography Course. Department of Anesthesia \& Interdivision of Critical Care, University of Toronto, Toronto, Ontario, Canada.

02.11.2016 Speaker. Sonic highways: The dark side of the moon. Canadian Critical Care Forum. Pre-Symposium Course. Toronto, Ontario, Canada.

02.11.2016 Speaker. Sonic highways: Let's get it started: Critical care ultrasound: Goals Limitations and training. Canadian Critical Care Forum. Pre-Symposium Course. Toronto, Ontario, Canada.

29.10.2016 Course Director. Point-of-care ultrasound in acute care medicine - Basic and advanced applications workshop. Canadian Critical Care Forum. PreSymposium Course. Toronto, Ontario, Canada.

27.06.2016 Speaker. Point of care ultrasound. Where are we going and how do we get there? Canadian Anesthesiologists' Society Meeting. Vancouver, British Columbia, Canada.

24.06.2016 Course Director. First Canadian perioperative point-of-care ultrasound course Canadian Anesthesiologists' Society Meeting. Vancouver, British Columbia, Canada.

14.05.2016 Speaker. Lung ultrasound workshop. McGill University Department of Anesthesia: Annual Update. Montreal, Quebec, Canada.

07.05.2016 Speaker. Cardiac tamponade. Second Canadian Winfocus Echocardiography Course. Winfocus: Basic Echocardiography Course. Department of Anesthesia \& Interdivision of Critical Care, University of Toronto, Toronto, Ontario, Canada.

07.05.2016 Speaker. Lung US. Second Canadian Winfocus Echocardiography Course. Winfocus: Basic Echocardiography Course. Department of Anesthesia \& Interdivision of Critical Care, University of Toronto, Toronto, Ontario, Canada.

07.05.2016 Course Director. Second Canadian Winfocus Echocardiography Course. Winfocus: Basic Echocardiography Course. Department of Anesthesia \& Interdivision of Critical Care, University of Toronto, Toronto, Ontario, Canada.

07.05.2016 Course Co-Director. Second Canadian Winfocus Echocardiography Course. Winfocus: Basic Echocardiography Course. Department of Anesthesia \& Interdivision of Critical Care, University of Toronto, Toronto, Ontario, Canada.

25.10.2015 Speaker. Introduction to TEE. Canadian Critical Care Forum. Toronto, Ontario, Canada.

24.10.2015 Speaker. Focused TTE: Get the views. Canadian Critical Care Forum. Toronto, Ontario, Canada. 
24.10.2015 Speaker. Focused cardiac ultrasound for pericardial effusion (and principles of tamponade physiology) Basic assessment of fluid responsiveness. Canadian Critical Care Forum. Toronto, Ontario, Canada.

24.10.2015 Course Director. First Canadian Point of Care Ultrasound Symposium in Critical Care. Point-of-care ultrasound in acute care medicine - basic and advanced applications workshop. Canadian Critical Care Forum. Toronto, Ontario, Canada.

21.06.2015 Speaker. Choosing wisely Canada: How to do better with less. Transthoracic echocardiography in asymptomatic patients. Canadian Anesthesiologist Society. Ottawa, Ontario, Canada.

21.06.2015 Chair. Introduction to pulmonary ultrasound. Canadian Anesthesiologist Society. Ottawa, Ontario, Canada. Presenter(s): Meineri M, Van Rensburg A, Moreno J, Mashari A.

18.04.2015 Course Co-Director. First Canadian Winfocus Echocardiography Course. Winfocus: Basic Echocardiography Course. Department of Anesthesia \& Interdivision of Critical Care, University of Toronto, Toronto, Ontario, Canada.

16.06.2014 Chair. Bedside PICC line insertion workshop. Canadian Anesthesiologists' Society. Saint John's, Newfoundland and Labrador, Canada.

15.06.2014 Facilitator. FOCUS cardiac ultrasound workshop. Canadian Anesthesiologists' Society. Saint John's, Newfoundland and Labrador, Canada.

16.05.2014 Speaker. Point of care ultrasound in the assessment of RV function. Society of Critical Care Anesthesiologists Annual Meeting. Montreal, Quebec, Canada.

11.05.2014 Speaker. Point of care ultrasound diagnosis of chest pain. Critical Care Ultrasound Institute. Montreal, Quebec, Canada.

10.05.2014 Facilitator. Point of care echocardiography workshops. Critical Care Ultrasound Institute. Montreal, Quebec, Canada.

24.06.2013 Facilitator. Thoracic anesthesia workshop. Canadian Anesthesiologists' Society. Alberta, Canada.

22.06.2013 Chair. Bedside PICC line insertion workshop. Canadian Anesthesiologists' Society. Alberta, Canada.

26.05.2013 Speaker. TEE for mechanical circulatory support. Critical Care Ultrasound Institute. Montreal, Quebec, Canada.

25.05.2013 Facilitator. Transthoracic echocardiography workshop. Critical Care Ultrasound Institute. Montreal, Quebec, Canada.

25.05.2013 Speaker. Basic Transthoracic Echocardiography views. Critical Care Ultrasound Institute. Montreal, Quebec, Canada.

16.06.2012 Chair. PICC Line insertion workshop. Canadian Anesthesiologists Society. Quebec City, Quebec, Canada. 
16.06.2012 Facilitator. FOCUS TTE workshop. Canadian Anesthesiologists Society. Quebec City, Quebec, Canada.

28.06.2011 Speaker. Surgical airway: Enhancing your skills of cricothiroidotomy from mannequin to hybrid pig trachea - high fidelity patient simulator to human cadavers. Canadian Anesthesiologists' Society Annual Meeting. Toronto, Ontario, Canada.

27.06.2011 Speaker. Interesting TEE cases. Canadian Anesthesiologists' Society Annual Meeting. Toronto, Ontario, Canada.

09.06.2011 Visiting Professor. 3D TEE for TAVi and HOCM. Department of Anesthesia, Universite' de Montreal, Institut de Cardiologie de Montreal, combined Grand Rounds. Montreal, Quebec, Canada.

28.06.2010 Speaker. Integrating 3D TEE into your practice: Ventricular assessment by 3D. Canadian Anesthesiologists' Society Annual Meeting. Montreal, Quebec, Canada.

26.06.2009 Speaker. TEE: New technologies: Real-time 3D TEE. Canadian Anesthesiologists' Society Annual Meeting. Vancouver, British Columbia, Canada. 


\subsection{Danksagung}

Mein Dank geht an:

Herrn Prof. Dr. med. Jörg Ender für die Leitung und die sehr gute Betreuung.

Dr. Azad Mashari, Joshua Qua Hiansen und die Advance Perioperative Laboratory bei Toronto Genral Hospital für ihre Unterstützung, Zusammenarbeit und Freundschaft.

Frau Andrea Mewes für die wichtige Unterstützung. 